\title{
Thermal, spectroscopic, X-ray and theoretical studies of metal complexes (sodium, manganese, copper, nickel, cobalt and zinc) with pyrimidine-5-carboxylic and pyrimidine-2-carboxylic acids
}

\author{
G. Świderski ${ }^{1}$ (I) $\cdot$ R. Świsłocka ${ }^{1} \cdot$ R. Łyszczek $^{2} \cdot$ S. Wojtulewski ${ }^{3} \cdot$ M. Samsonowicz ${ }^{1} \cdot$ W. Lewandowski ${ }^{1}$
}

Received: 14 November 2018/ Accepted: 19 July 2019/Published online: 16 September 2019

(c) The Author(s) 2019

\begin{abstract}
The new $3 \mathrm{~d}$ metal complexes of pyrimidine-2-carboxylic (2PCA) and pyrimidine-5-carboxylic (5PCA) acids were synthesized and characterized using thermal analysis (TG-DSC, TG-FTIR), X-ray, spectroscopic (IR, Raman) methods and theoretical (DFT) studies. In the complexes of pyrimidine-2-carboxylic acid of the general formula $\mathrm{M}(2 \mathrm{PCA})_{2} \cdot x \mathrm{H}_{2} \mathrm{O}$ (where 2PCA-pyrimidine-2-carboxylate; $\mathrm{M}=\mathrm{Mn}(\mathrm{II}), \mathrm{Co}(\mathrm{II}), \mathrm{Ni}(\mathrm{II}), \mathrm{Cu}(\mathrm{II})$ and $\mathrm{Zn} ; x=0$ for $\mathrm{Mn}$ and $\mathrm{Cu} ; x=2$ for $\mathrm{Co}, \mathrm{Ni}$ and $\mathrm{Zn}$ ) coordination of metal ions occurs through nitrogen atom from pyrimidine ring and carboxylate oxygen atom. The complexes of pyrimidine-5-carboxylic acid of the general formula $\mathrm{M}(5 \mathrm{PCA})_{2} \cdot x \mathrm{H}_{2} \mathrm{O}$ (where 5PCA-pyrimidine-5-carboxylate; $\mathrm{M}=\mathrm{Mn}(\mathrm{II}), \mathrm{Co}(\mathrm{II}), \mathrm{Ni}(\mathrm{II}), \mathrm{Cu}(\mathrm{II})$ and $\mathrm{Zn} ; x=6$ for $\mathrm{Cu}$ and 4 for remaining complexes) were obtained as monomeric isostructural compounds. Coordination of metal centers occurs through two nitrogen atom from different pyrimidine-5-carboxylate ligand and four oxygen atoms from water molecules. The IR and Raman spectra of free acids as well as obtained metal(II) complexes were described in detail. Aromaticity (HOMA, EN, GEO and $\mathrm{I}_{6}$ ) of complexes was determined and discussed. The investigated compounds decompose in air in two main stages connected with dehydration and decomposition/burning of anhydrous compounds to the suitable metal oxides. Thermal decomposition in nitrogen leads to the evolution of water, carbon oxides, ammonia and pyrimidine molecules.
\end{abstract}

Keywords Pyrimidine-2-carboxylic acid · Pyrimidine-5-carboxylic acid · $3 \mathrm{~d}$ metal complexes · Aromaticity indices . Thermal analysis

\section{Introduction}

Complexes of transition metals ( $\mathrm{Co}, \mathrm{Mn}, \mathrm{Ni}, \mathrm{Zn}, \mathrm{Cu}$ ) play an important role in the life processes of living organisms. They are, among others, components of enzymes, proteins and vitamins; they participate in oxidation-reduction

G. Świderski

g.swiderski@pb.edu.pl

1 Department of Chemistry, Biology and Biotechnology, Faculty of Civil Engineering and Environmental Engineering, Bialystok University of Technology, Wiejska 45E, 15-351 Białystok, Poland

2 Department of General and Coordination Chemistry, Faculty of Chemistry, Maria Curie-Skłodowska University, M.C. Skłodowskiej Sq. 2, 20-031 Lublin, Poland

3 Institute of Chemistry, University of Bialystok, Ciolkowskiego 1 K, 15-245 Białystok, Poland processes or in binding, storage and transport of oxygen [1]. Many years ago, it was noticed that some complex compounds of transition metals, including copper and zinc, may react with the superoxide anion radical in a manner reminiscent of the activity of native superoxide dismutases. Hence, they were called superoxide dismutase mimetics SOD [2]. Ligands that are heterocyclic nitrogen bases have a significant effect on increasing the reactivity of copper(II) complexes with superoxide anion radicals. Although copper(II) complexes show a weaker antioxidant effect than the SOD enzyme, they are important as potential superoxide dismutase mimetics due to the low molecular weight $[3,4]$. Complexes of transition metals have also been used as medicines. In many cases, the ligand responsible for the therapeutic effect of the drug may increase efficacy action after the complexation by metal. Metal ions in complexes with antitumor active ligands play the role as modulators of activity [5]. The metal affects the redox activity of the 
ligand, its mode of action, therapeutic efficacy, solubility, stability and a number of other properties [6]. Complexation by the metals effects on the change in the distribution of electronic charge in the ligand, which translates into a change in the physicochemical and biological properties of the chemical compound [7-10]. Studies have shown that transition metals influence the stability of the electron system of complexes the aromatic acids [11-14]. This impact depends not only on the properties of metal, but also on the way the ligand-metal coordination. In complexes of heteroaromatic acids, the metal may be attached via a carboxyl anion and heteroatoms of the aromatic ring. These types of binding are formed inter alia in the pyridine2-carboxylic, pyrazine-2-carboxylic or pyrimidine-2-carboxylic acid complexes [15-18]. The pyrimidine-5-carboxylic acid may form complexes by attaching a metal via a ring nitrogen atom without the participation of a carboxylic group [19].

In the pyridinecarboxylic acid complexes, various types of metal-ligand coordination depending on the position of the nitrogen atom relative to the carboxylic group were observed [20-28]. In the case of 2-pyridinecarboxylic acid (picolinic acid) in which the nitrogen atom is located in close proximity to the carboxyl group, the metal is coordinated through the carboxyl group and the nitrogen atom to form a chelate ring [20-22]. In the case of nicotinic acid, a type of coordination through the carboxylic group was observed [23-25]. In the case of isonicotinic acid, the formation of complexes with coordination of metal-nitrogen atom and metal-carboxylic group was noticed [26-28]. It was found that the method of coordination affects the electronic structure of the aromatic system as well as the thermal properties of the complex [29,30].

Zinc complexes with pyridinecarboxylic acids (nicotinic, picolinic, isonicotinic) show different thermal stability. Studies have shown that the complex with picolinic acid (coordination $\mathrm{O}, \mathrm{N}$ ) is less thermally stable than complexes with nicotinic acid and isonicotinic acid $[29,30]$.

In the present work, complexes of pyrimidinecarboxylic acids were investigated. Carboxylic acids derived from diazines (Fig. 1) due to the number of potential chelating sites can form various coordination structures in relationships with metal ions $[18,19,31,32]$. The pyrimidine derivatives are found in living organisms where they play a fundamental role in many life processes. The most important naturally occurring pyrimidines are the pyrimidine uracil bases, thymine and cytosine, which are the basic building blocks of nucleosides in deoxyribonucleic acid (DNA) and ribonucleic acid (RNA).

Many of the pyrimidine derivatives show a wide range of biological activities and are known for their anticancer (fluorouracil) [33], antimicrobial, analgesic, antiviral (also in the treatment of HIV, hepatitis B), antimalarial and anesthetic [34] properties. Some of the pyrimidine derivatives have been used as plant protection products [35]. Orotic acid is commonly known as a precursor in pyrimidine biosynthesis [36]. As a component of the daily diet is found in milk and other dairy products. In the body, it is transformed into uridine, which then participates in the pyrimidine recovery pathway in the kidneys, liver and erythrocytes [37].

In order to improve the bioavailability of orotic acid, its combinations with organic cations (e.g., choline, carnitine) or metal ions $\left(\mathrm{Mg}^{2+}, \mathrm{Zn}^{2+}, \mathrm{Ca}^{2+}, \mathrm{K}^{+}\right)$are used. Such combinations may be used in the therapy of metabolic syndromes and in bodybuilding [38].

The aim of the work was to obtain complexes of transition metals $3 \mathrm{~d}$ with carboxylic acid pyrimidine derivatives. A series of complexes with ligands having different carboxylic acid positions relative to the nitrogen atoms in the aromatic ring (pyrimidine-2-carboxylic acid and pyrimidine-5-carboxylic acid) were synthesized. The influence of the metal on the electron system of the ligand and the thermal properties of the obtained complexes depending on the type of metal-ligand coordination were evaluated.

\section{Experimental}

\section{Synthesis of complexes}

The complexes of manganese(II), cobalt(II), nickel(II), zinc and copper(II) with pyrimidine-2-carboxylic (2PCA) acid complexes were prepared as follows: $49.6 \mathrm{mg}$ of acid was added to the stoichiometric quantity of sodium hydroxide $\left(4 \mathrm{~cm}^{3} ; 0.1 \mathrm{~mol} \mathrm{dm}^{-3}\right)$. The suspension was placed in an ultrasonic bath at $70{ }^{\circ} \mathrm{C}$ until the acid dissolved. Then, $2 \mathrm{~cm}^{3}$ of metal(II) chloride solution $\left(0.1 \mathrm{~mol} \mathrm{dm}{ }^{-3}\right)$ was added. The solution was shaken on a shaker for $1 \mathrm{~h}$ at room temperature, and the complexes were allowed to stand. The obtained precipitates/or crystals were washed with water to rinse the chlorides under the control of $\mathrm{AgNO}_{3}$ solution. Analogously, metal(II) pyrimidine-5-carboxylate complexes were obtained.

\section{Elemental analysis}

The elementary analysis was carried out using the CHN 2400 PerkinElmer Analyzer. The water content was determined from the thermogravimetric curves. Table 1 presents the results of elemental analysis of pyrimidine-2carboxylic acid complexes, and Table 2 presents the results of elemental analysis for pyrimidine-5-carboxylic acid complexes. 
Fig. 1 Structures of pyrimidinecarboxylic acids

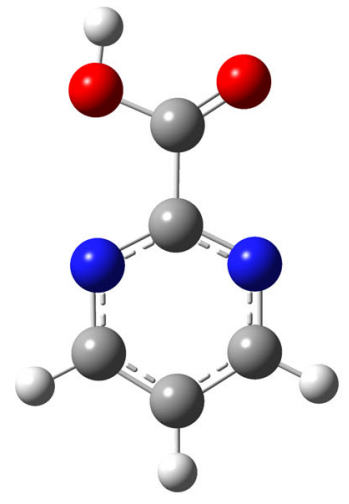

Pyrimidine-2-carboxylic acid

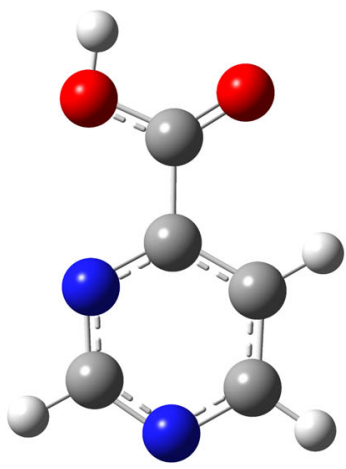

Pyrimidine-4-carboxylic acid

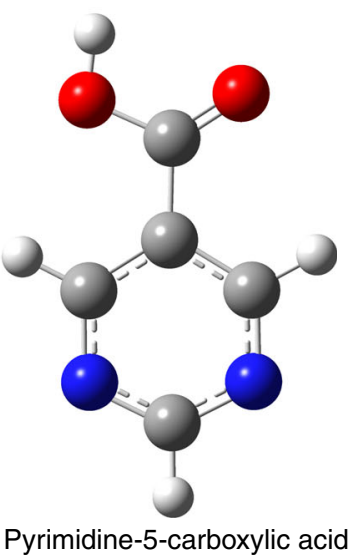

Table 1 Elemental analysis for pyrimidine-2-carboxylates

\begin{tabular}{|c|c|c|c|c|c|c|c|c|c|}
\hline \multirow{2}{*}{ Compound name } & \multirow[t]{2}{*}{ Formula } & \multicolumn{2}{|c|}{ Content $\mathrm{C} / \%$} & \multicolumn{2}{|c|}{ Content $\mathrm{H} / \%$} & \multicolumn{2}{|c|}{ Content N/\% } & \multirow{2}{*}{ Yield/\% } & \multirow[t]{2}{*}{ Color } \\
\hline & & Calc. & Exp. & Calc. & Exp. & Calc. & Exp. & & \\
\hline Manganese pyrimidine-2-carboxylate & $\operatorname{Mn}(2 \mathrm{PCA})_{2}$ & 39.89 & 39.32 & 2.01 & 1.99 & 18.61 & 18.14 & 80 & Yellow \\
\hline Cobalt pyrimidine-2-carboxylate & $\mathrm{Co}(2 \mathrm{PCA})_{2} \cdot \mathrm{H}_{2} \mathrm{O}$ & 35.21 & 35.42 & 2.95 & 2.97 & 16.42 & 16.14 & 75 & Orange \\
\hline Nickel pyrimidine-2-carboxylate & $\mathrm{Ni}(2 \mathrm{PCA})_{2} \cdot 2 \mathrm{H}_{2} \mathrm{O}$ & 35.23 & 35.11 & 2.96 & 2.83 & 16.43 & 16.18 & $70-80$ & Green \\
\hline Zinc pyrimidine-2-carboxylate & $\mathrm{Zn}(2 \mathrm{PCA})_{2} \cdot 2 \mathrm{H}_{2} \mathrm{O}$ & 34.55 & 34.51 & 2.96 & 2.81 & 16.43 & 16.27 & 75 & White \\
\hline Copper pyrimidine-2-carboxylate & $\mathrm{Cu}(2 \mathrm{PCA})_{2}$ & 38.78 & 38.63 & 1.95 & 1.91 & 18.09 & 18.16 & 70 & Blue \\
\hline
\end{tabular}

$2 \mathrm{PCA}=\mathrm{C}_{5} \mathrm{H}_{3} \mathrm{~N}_{2} \mathrm{O}_{2}$

Table 2 Elemental analysis for pyrimidine-5-carboxylates

\begin{tabular}{|c|c|c|c|c|c|c|c|c|c|}
\hline \multirow[t]{2}{*}{ Compound name } & \multirow[t]{2}{*}{ Formula } & \multicolumn{2}{|c|}{ Content $\mathrm{C} / \%$} & \multicolumn{2}{|c|}{ Content $\mathrm{H} / \%$} & \multicolumn{2}{|c|}{ Content N/\% } & \multirow[t]{2}{*}{ Yield/\% } & \multirow[t]{2}{*}{ Color } \\
\hline & & Calc. & Exp. & Calc. & Exp. & Calc. & Exp. & & \\
\hline Manganese pyrimidine-5-carboxylate & $\mathrm{Mn}(5 \mathrm{PCA})_{2} \cdot 4 \mathrm{H}_{2} \mathrm{O}$ & 32.18 & 32.20 & 3.78 & 3.69 & 15.01 & 14.55 & 80 & Yellow \\
\hline Cobalt pyrimidine-5-carboxylate & $\mathrm{Co}(5 \mathrm{PCA})_{2} \cdot 4 \mathrm{H}_{2} \mathrm{O}$ & 31.84 & 31.51 & 3.74 & 3.68 & 14.85 & 14.44 & $75-80$ & Orange \\
\hline Nickel pyrimidine-5-carboxylate & $\mathrm{Ni}(5 \mathrm{PCA})_{2} \cdot 4 \mathrm{H}_{2} \mathrm{O}$ & 31.86 & 30.84 & 3.74 & 3.77 & 14.86 & 14.02 & 80 & Green \\
\hline Zinc pyrimidine-5-carboxylate & $\mathrm{Zn}(5 \mathrm{PCA})_{2} \cdot 4 \mathrm{H}_{2} \mathrm{O}$ & 31.31 & 31.42 & 3.68 & 3.55 & 14.60 & 14.34 & 85 & White \\
\hline Copper pyrimidine-5-carboxylate & $\mathrm{Cu}(5 \mathrm{PCA})_{2} \cdot 6 \mathrm{H}_{2} \mathrm{O}$ & 28.75 & 28.57 & 4.34 & 4.25 & 13.41 & 13.30 & $70-80$ & Blue \\
\hline
\end{tabular}

$5 \mathrm{PCA}=\mathrm{C}_{5} \mathrm{H}_{3} \mathrm{~N}_{2} \mathrm{O}_{2}$

\section{Thermal analysis}

Thermal analyses of the investigated complexes were carried out by the thermogravimetric (TG) and differential scanning calorimetry (DSC) methods using the Setsys 16/18 analyzer Setaram). The samples (about 5-8 mg) were heated in alumina crucibles in the range of $30-1000{ }^{\circ} \mathrm{C}$ at a heating rate of $10{ }^{\circ} \mathrm{C} \mathrm{min}^{-1}$ in flowing air atmosphere $\left(v=0.75 \mathrm{dm}^{3} \mathrm{~h}^{-1}\right)$. The TG-FTIR coupled measurements performed on Q5000 (TA) apparatus coupled with the Nicolet 6700 spectrophotometer. The samples of about $20-30 \mathrm{mg}$ were heated in platinum crucibles from room temperature up to $700{ }^{\circ} \mathrm{C}$ at a heating rate of $20^{\circ} \mathrm{C} \mathrm{min}^{-1}$ in flowing nitrogen atmosphere $\left(25 \mathrm{~cm}^{3} \min ^{-1}\right)$.

\section{FTIR and Raman study}

The FTIR spectra were recorded with an Alfa (Bruker) spectrometer within the range of $400-4000 \mathrm{~cm}^{-1}$. Samples in the solid state were measured in $\mathrm{KBr}$ matrix pellets and ATR technique. FT-Raman spectra of solid samples were recorded in the range of $400-4000 \mathrm{~cm}^{-1}$ with a MultiRam (Bruker) spectrometer. 


\section{Theoretical calculations}

To calculate optimized geometrical structures of pyrimidinecarboxylic acids and copper(II) complexes, the quantum-mechanical method was used: density functional (DFT) hybrid method B3LYP with non-local correlation provided by Lee-Young-Parr expression. All calculations for acids were carried out in functional base 6-311++G(d,p) and for acids and copper complexes in LANL2DZ base. Calculations were performed using the Gaussian09 package [39]. Experimental spectra were interpreted in terms of calculated at DFT method in B3LYP/6-311++G(d,p) level and literature data [40, 41]. Theoretical wavenumbers were scaled according to the formula: $\quad v_{\text {scaled }}=0.98 \cdot v_{\text {calculated }}$ for B3LYP/6$311++G(d, p)$ level method. Spectral assignments used the normal oscillation of the pyrimidine ring measured using B3LYP/6-311++G(d,p).

The aromaticity indices (HOMA, GEO, EN, $\mathrm{I}_{6}$ ) were calculated for geometric structures (theoretical and calculated) of pyrimidine-2-carboxylates and pyrimidine-5-carboxylates. The HOMA index (harmonic oscillator model of aromaticity) differs from all other geometry-based ones by assuming another reference bond length. In this model, instead of the mean bond length a concept of the optimal bond length is applied [42, 43]:

$$
\begin{aligned}
\text { HOMA } & =1-\left[\alpha\left(R_{\mathrm{opt}}-R_{\mathrm{av}}\right)^{2}+\frac{\alpha}{n} \sum\left(R_{\mathrm{av}}-R_{\mathrm{i}}\right)^{2}\right] \\
& =1-\mathrm{EN}-\mathrm{GEO}
\end{aligned}
$$

within the confines of the HOMA model, it is possible to obtain two components which describe different contribution to decrease in aromaticity, i.e., (a) due to bond elongation (the EN component) and (b) due to bond length alternation (the GEO component). The value of HOMA index is equal 1 for the entire aromatic system; HOMA $=0$ when the structure is non-aromatic and HOMA $<0$ for anti-aromatic ring.

The value of the Bird's aromaticity index $\left(\mathrm{I}_{5}, \mathrm{I}_{6}\right)$ describes the equation [44]:

$I=100\left\{1-\left(V / V_{\mathrm{k}}\right)\right\}$

where $V_{\mathrm{k}}$ is for the five-membered rings 35 and the sixmembered 33.3, and $V$ is calculated from the equation:

$V=\left(100 / n_{\mathrm{av}}\right)\left[\sum_{r=1}^{n}\left(n_{\mathrm{r}}-n_{\mathrm{av}}\right)^{2} / n\right]^{\frac{1}{2}}$

where $n_{\mathrm{av}}$-average binding order, $n$-bond order based on bond length: $n=(a / R)-\mathrm{b}$, a and b-parameters depending on the type of atoms in the bond.

\section{SOD activity and HOMO, LUMO energies}

SOD activity for copper(II) complexes was determined theoretically on the basis of the energy calculations for geometrically optimized structures. As a theoretical parameter defining the radical scavenging activity by the studied complexes, HOMO and LUMO energy values and EA affinity value were selected:

TEE-Cu(I)-TEE-Cu(II), where TE E-Cu(I) is the total energy of the complex $\mathrm{E}-\mathrm{Cu}(\mathrm{I})$ and TEE-Cu(II) with the total energy of the $\mathrm{E}-\mathrm{Cu}$ (II) complex.

\section{X-ray analysis}

Suitable crystals were sequentially mounted on a fiber loop and used for X-ray measurements. X-ray data were collected on the Oxford Diffraction SuperNova DualSource diffractometer with use of the monochromated $\mathrm{CuK} \alpha \mathrm{X}$-ray source $(\lambda=1.54184)$. The crystals were kept at $100 \mathrm{~K}$ during data collection. Data reduction and analytical absorption correction were performed with CrysAlis PRO [45]. Using Olex2 [46], the structures were solved with the ShelXS [47] structure solution program using Direct Methods and refined with the ShelXL [47] refinement package using Least Squares minimization.

The non-hydrogen atoms were refined anisotropically. The positions of $\mathrm{OH}$ hydrogen atoms were found on a Fourier difference map and refined. Hydrogen atoms of aromatic ring were introduced in calculated positions with idealized geometry and constrained using a rigid body model with isotropic displacement parameters equal to 1.2 of the equivalent displacement parameters of the parent atoms. Summaries of relevant crystallographic data are given in Tables 3 and 6 for pyrimidine-2-carboxylate and pyrimidine-5-carboxylate complexes. The supplementary crystallographic data for this paper can be obtained free of charge from The Cambridge Crystallographic Data Centre via www.ccdc.cam.ac.uk/data_request/cif.

\section{Results}

\section{Crystal structure description}

Isostructural copper(II) and zinc(II) pyrimidine-2-carboxylates $\mathrm{M}(2 \mathrm{PCA})_{2} \cdot 2 \mathrm{H}_{2} \mathrm{O}$ crystallize in the monoclinic $P 2_{1} / c$ space group (Table 3 ). The asymmetric unit is a half of the complex molecule, and the metal cations are located on a crystallographic inversion center. The cobalt and zinc metal cations are coordinated identically by two pyrimidine-2-carboxylate ligands in the equatorial plane and by two water molecules in the axial positions. The pyrimidine- 
Table 3 Crystal data and structure refinement of pyrimidine-2-carboxylates

\begin{tabular}{|c|c|c|}
\hline Empirical formula & $\mathrm{Co}\left(\mathrm{C}_{5} \mathrm{H}_{4} \mathrm{~N}_{2} \mathrm{O}_{2}\right)_{2} \cdot 2 \mathrm{H}_{2} \mathrm{O}$ & $\mathrm{Zn}\left(\mathrm{C}_{5} \mathrm{H}_{4} \mathrm{~N}_{2} \mathrm{O}_{2}\right)_{2} \cdot 2 \mathrm{H}_{2} \mathrm{O}$ \\
\hline Formula weight & 341.15 & 347.59 \\
\hline Crystal system & Monoclinic & Monoclinic \\
\hline Space group & $P 2_{1} / \mathrm{c}$ & $P 2{ }_{1} / \mathrm{c}$ \\
\hline$a / \AA$ & $5.201(7)$ & $5.234(1)$ \\
\hline$b / \AA$ & $11.713(2)$ & $11.726(3)$ \\
\hline$c / \AA$ & $10.041(7)$ & $9.793(8)$ \\
\hline$\alpha /^{\circ}$ & 90 & 90 \\
\hline$\beta /^{\circ}$ & $96.448(4)$ & $97.8387(12)$ \\
\hline$\gamma /{ }^{\circ}$ & 90 & 90 \\
\hline Volume $/ \AA^{3}$ & $607.9(5)$ & $595.4(8)$ \\
\hline$Z$ & 2 & 2 \\
\hline$\rho_{\text {calc }} / \mathrm{g} \mathrm{cm}^{-3}$ & 1.864 & 1.939 \\
\hline Crystal size $/ \mathrm{mm}^{3}$ & $0.312 \times 0.091 \times 0.091$ & $0.317 \times 0.153 \times 0.109$ \\
\hline Final $R$ indexes $[\mathrm{I} \geq 2 \sigma(\mathrm{I})]$ & $R_{1}=0.0308, w R_{2}=0.0794$ & $R_{1}=0.0268, w R_{2}=0.0705$ \\
\hline Final $R$ indexes [all data] & $R_{1}=0.0367, w R_{2}=0.0824$ & $R_{1}=0.0272, w R_{2}=0.0708$ \\
\hline Largest diff. peak/hole/e $\AA^{-3}$ & $0.25 /-0.56$ & $0.33 /-0.70$ \\
\hline CCDC no. & $1,577,381$ & $1,857,354$ \\
\hline
\end{tabular}

2-carboxylate ligands are bound to metal cations in a bidentate $\mathrm{N}, \mathrm{O}$-chelate mode, forming five-membered rings (Fig. 2). The bonds of the coordination sphere M-N1, M$\mathrm{O} 1$ and $\mathrm{M}-\mathrm{Ow}$ are nearly equal in length (2.066(1)2.123(2) $\AA$ ), and the overall coordination sphere around cobalt and zinc cations can be described as an octahedral. However, the analysis of the valence angles $\mathrm{O}-\mathrm{M}-\mathrm{Ow}$ and $\mathrm{O}-\mathrm{M}-\mathrm{N}$ reveal a small distortion of the coordination spheres, since the $\mathrm{N} 1-\mathrm{Co}-\mathrm{O} 1 \mathrm{w}$ and $\mathrm{N} 1-\mathrm{Zn}-\mathrm{O} 1$ valence angles are not a right angles and equal 79.5(5) and 79.9(6) degrees, respectively (Table 4).

The hydrogen bonds patterns are marked in Fig. 3 as a dashed line. There are three intermolecular hydrogen bonds in the crystal structure of $\mathrm{Co}$ and $\mathrm{Zn}$ pyrimidine-2-carboxylate complexes. Two of them are $\mathrm{O}-\mathrm{H}^{\cdots} \mathrm{O}$ type and one is $\mathrm{O}-\mathrm{H}^{\cdots} \mathrm{N}$ type. Coordinated water molecules acts as a proton donor, while $\mathrm{O} 1$ (coordinated), $\mathrm{O} 2$ (uncoordinated) and N3 (uncoordinated) atoms play a role of the proton

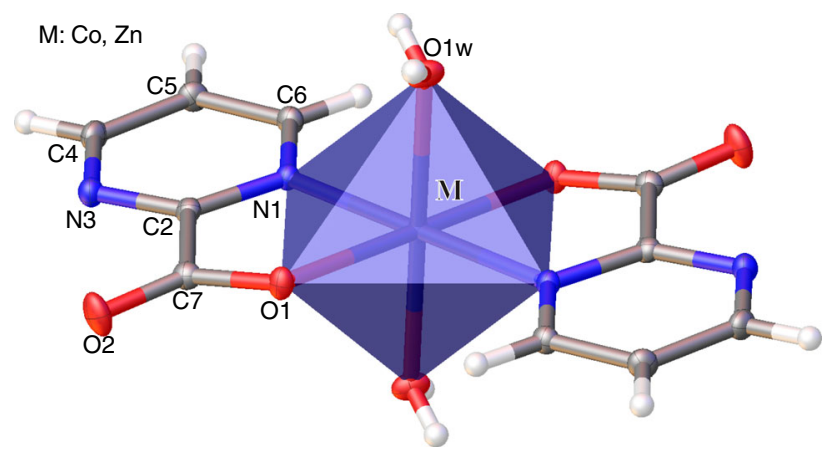

Fig. 2 The molecular structure of the $\mathrm{Co}(\mathrm{II})$ and $\mathrm{Zn}$ pyrimidine-2carboxylates complexes
Table 4 Selected geometrical parameters of cobalt (II) and zinc pyrimidine-2-carboxylates complexes

\begin{tabular}{lrr}
\hline A, ${ }^{\circ}$ & \multicolumn{1}{c}{$\mathrm{Co}$} & $\mathrm{Zn}$ \\
\hline $\mathrm{N} 1-\mathrm{C} 2$ & $1.337(2)$ & $1.338(2)$ \\
$\mathrm{C} 2-\mathrm{N} 3$ & $1.324(2)$ & $1.328(2)$ \\
$\mathrm{N} 3-\mathrm{C} 4$ & $1.337(3)$ & $1.341(2)$ \\
$\mathrm{C} 4-\mathrm{C} 5$ & $1.381(3)$ & $1.387(2)$ \\
$\mathrm{C} 5-\mathrm{C} 6$ & $1.380(3)$ & $1.384(2)$ \\
$\mathrm{C} 6-\mathrm{N} 1$ & $1.335(3)$ & $1.337(2)$ \\
$\mathrm{C} 5-\mathrm{C} 7$ & $1.528(3)$ & $1.533(2)$ \\
$\mathrm{C} 7-\mathrm{O} 1$ & $1.275(2)$ & $1.280(2)$ \\
$\mathrm{C} 7-\mathrm{O} 2$ & $1.222(3)$ & $1.228(2)$ \\
$\mathrm{M}-\mathrm{O} 1$ & $2.066(1)$ & $2.082(2)$ \\
$\mathrm{M}-\mathrm{N} 1$ & $2.114(1)$ & $2.103(5)$ \\
$\mathrm{M}-\mathrm{O} 1 \mathrm{w}$ & $2.094(1)$ & $2.123(2)$ \\
$\mathrm{N} 1-\mathrm{C} 2-\mathrm{N} 3$ & $125.8(2)$ & $125.5(1)$ \\
$\mathrm{C} 2-\mathrm{N} 3-\mathrm{C} 4$ & $116.2(2)$ & $116.4(1)$ \\
$\mathrm{N} 3-\mathrm{C} 4-\mathrm{C} 5$ & $122.4(2)$ & $122.4(1)$ \\
$\mathrm{C} 4-\mathrm{C} 5-\mathrm{C} 6$ & $117.1(2)$ & $116.8(1)$ \\
$\mathrm{C} 5-\mathrm{C} 6-\mathrm{N} 1$ & $121.1(2)$ & $121.1(1)$ \\
$\mathrm{C} 6-\mathrm{N} 1-\mathrm{C} 2$ & $117.4(2)$ & $117.7(1)$ \\
$\mathrm{C} 2-\mathrm{C} 7-\mathrm{O} 1$ & $115.4(2)$ & $115.3(1)$ \\
$\mathrm{C} 2-\mathrm{C} 7-\mathrm{O} 2$ & $118.5(2)$ & $118.0(1)$ \\
$\mathrm{O} 1-\mathrm{M}-\mathrm{O} 1 \mathrm{~W}$ & $91.8(6)$ & $87.3(5)$ \\
$\mathrm{O} 1-\mathrm{M}-\mathrm{N} 1$ & $91.4(7)$ & \\
$\mathrm{O} 1 \mathrm{~W}-\mathrm{M}-\mathrm{N} 1$ & $79.5(5)$ & \\
\hline & & \\
& &
\end{tabular}

acceptors in hydrogen bonding. It is worth to emphasize that the hydrogen atom H1WB is a donor in a bifurcated (three-centered) hydrogen bond, where $\mathrm{O} 2$ and $\mathrm{N} 3$ atoms 


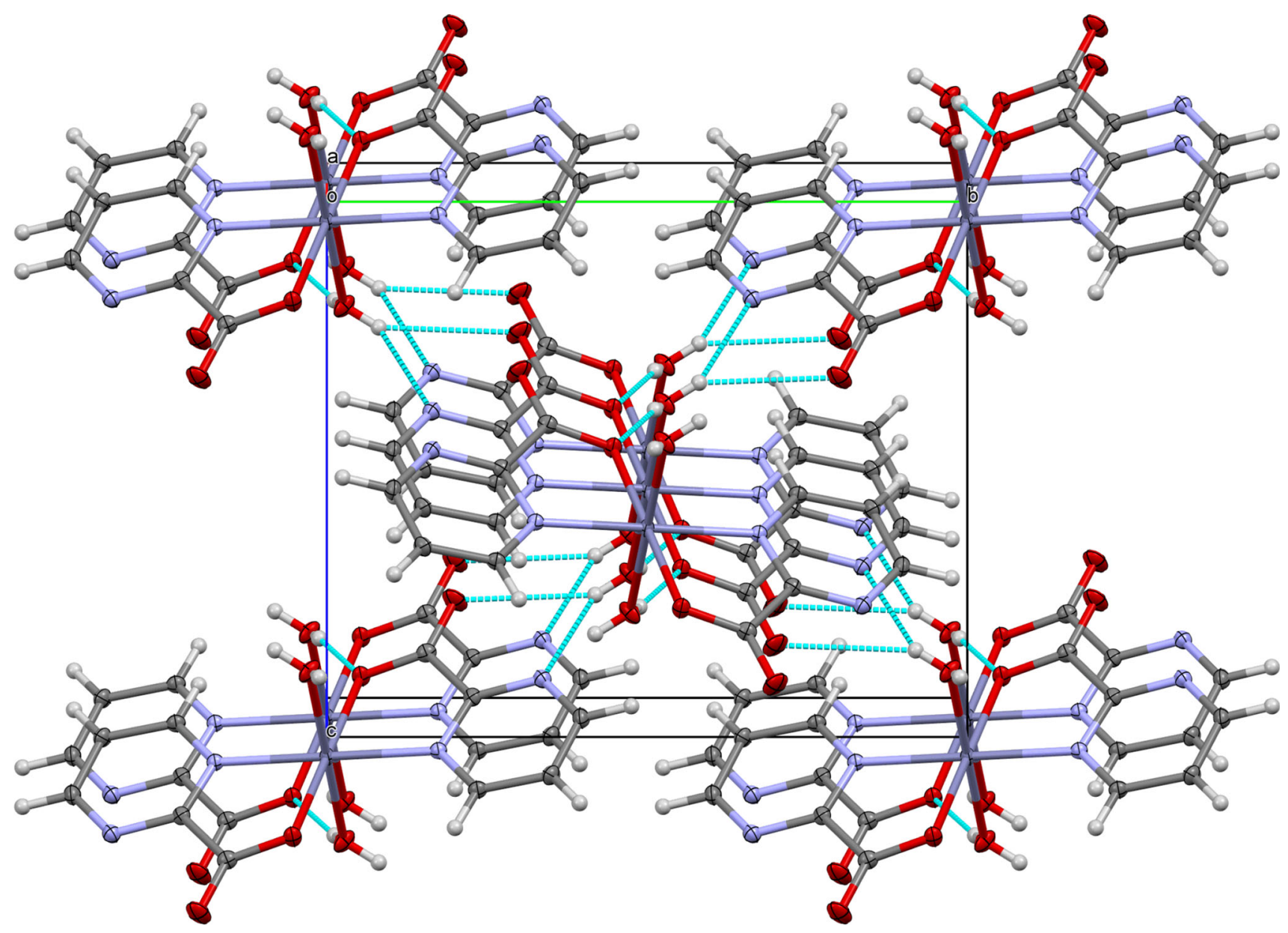

Fig. 3 Crystal structure of the Co(II) and Zn pyrimidine-2-carboxylates complexes. Hydrogen bonds are presented as a dashed lines

of the neighboring ligand molecule are acceptor centers. Selected geometrical parameters of the hydrogen bonds together with the symmetry codes (symm. op. 2) are presented in Table 5.

The complexes of manganese(II), cobalt(II) and zinc with pyrimidine-5-carboxylic acid of the formula $\mathrm{M}(5 \mathrm{PCA})_{2} \cdot 4 \mathrm{H}_{2} \mathrm{O}$ crystallize in the monoclinic $P 2_{1} / \mathrm{c}$ space group (Table 6). The crystal structure of copper complex $\mathrm{M}(5 \mathrm{PCA})_{2} \cdot 6 \mathrm{H}_{2} \mathrm{O}$ contains an additional uncoordinated water molecule, and the symmetry of the structure is significantly lower $(P \overline{1})$.

However, in all cases the asymmetric unit is a half of the complex molecule and the metal cations are located on a crystallographic inversion center. The metal cations are coordinated identically by two pyrimidine-5-carboxylate ligands and two water molecules in the equatorial plane and by two water molecules in the axial positions. The pyrimidine-5-carboxylate ligands are bound to metal

Table 5 Geometrical parameters of the hydrogen bonds of cobalt (II) and zinc pyrimidine-2-carboxylates complexes

\begin{tabular}{lllllllll}
\hline & $\mathrm{D}$ & $\mathrm{H}$ & $\mathrm{A}$ & $\mathrm{d}(\mathrm{D}-\mathrm{H}) / \AA$ & $\mathrm{d}(\mathrm{H}-\mathrm{A}) / \AA$ & $\mathrm{d}(\mathrm{D}-\mathrm{A}) / \AA$ & $\mathrm{D}-\mathrm{H}-\mathrm{A} /{ }^{\circ}$ & Symm. op. 2 \\
\hline Co & O1 W & H1 WA & O1 & $0.79(4)$ & 1.952 & $2.734(2)$ & $169(3)$ & $1-x, 1-y, 1-z$ \\
& O1 W & H1 WB & O2 & $0.72(5)$ & 2.601 & $3.229(3)$ & $147(4)$ & $x, 1 / 2-y,-1 / 2+z$ \\
& O1 W & H1 WB & N3 & $0.72(5)$ & 2.272 & $2.883(2)$ & $143(4)$ & $x, 1 / 2-y,-1 / 2+z$ \\
Zn & O1 W & H1 WA & O1 & $0.78(3)$ & 1.978 & $2.737(2)$ & $164(3)$ & $-1+x, y, z$ \\
& O1 W & H1 WB & O2 & $0.74(3)$ & 2.597 & $3.250(2)$ & $147(3)$ & $1-x,-1 / 2+y, 1.5-z$ \\
& O1 W & H1 WB & N3 & $0.74(3)$ & 2.236 & $2.858(2)$ & $142(3)$ & $1-x,-1 / 2+y, 1.5-z$ \\
\hline
\end{tabular}


Table 6 Crystal data and structure refinement of pyrimidine-5-carboxylates

\begin{tabular}{|c|c|c|c|c|}
\hline Empirical formula & $\mathrm{Mn}\left(\mathrm{C}_{5} \mathrm{H}_{4} \mathrm{~N}_{2} \mathrm{O}_{2}\right)_{2} \cdot 4 \mathrm{H}_{2} \mathrm{O}$ & $\mathrm{Co}\left(\mathrm{C}_{5} \mathrm{H}_{4} \mathrm{~N}_{2} \mathrm{O}_{2}\right)_{2} \cdot 4 \mathrm{H}_{2} \mathrm{O}$ & $\mathrm{Zn}\left(\mathrm{C}_{5} \mathrm{H}_{4} \mathrm{~N}_{2} \mathrm{O}_{2}\right)_{2} \cdot 4 \mathrm{H}_{2} \mathrm{O}$ & $\mathrm{Cu}\left(\mathrm{C}_{5} \mathrm{H}_{4} \mathrm{~N}_{2} \mathrm{O}_{2}\right)_{2} \cdot 4 \mathrm{H}_{2} \mathrm{O}, 2 \mathrm{H}_{2} \mathrm{O}$ \\
\hline Formula weight & 373.19 & 377.18 & 383.62 & 417.82 \\
\hline Crystal system & Monoclinic & Monoclinic & Monoclinic & Triclinic \\
\hline Space group & $P 2_{1} / \mathrm{c}$ & $P 2_{1} / \mathrm{c}$ & $P 2{ }_{1} / \mathrm{c}$ & $P-1$ \\
\hline$a / \AA ̊$ & $6.520(2)$ & $6.514(6)$ & $6.526(8)$ & $6.189(1)$ \\
\hline$b / \AA$ & $12.455(3)$ & $12.456(1)$ & $12.470(5)$ & $6.764(6)$ \\
\hline$c / \AA$ & $8.510(1)$ & $8.508(3)$ & $8.525(8)$ & $9.521(2)$ \\
\hline$\alpha l^{\circ}$ & 90 & 90 & 90 & $105.450(5)$ \\
\hline$\beta /^{\circ}$ & $98.089(6)$ & $98.12(2)$ & $98.03(5)$ & $92.93(7)$ \\
\hline$\gamma /{ }^{\circ}$ & 90 & 90 & 90 & $96.02(2)$ \\
\hline Volume $/ \AA^{3}$ & $684.24(2)$ & $683.50(3)$ & $687.12(4)$ & $380.79(4)$ \\
\hline$Z$ & 2 & 2 & 2 & 1 \\
\hline$\rho_{\text {calc }} / \mathrm{g} \mathrm{cm}^{-3}$ & 1.811 & 1.833 & 1.854 & 1.822 \\
\hline Crystal size $/ \mathrm{mm}^{3}$ & $0.179 \times 0.107 \times 0.092$ & $0.305 \times 0.163 \times 0.122$ & $0.259 \times 0.182 \times 0.182$ & $0.631 \times 0.303 \times 0.216$ \\
\hline Final $R$ indexes $[\mathrm{I} \geq 2 \sigma(\mathrm{I})]$ & $\begin{array}{l}R_{1}=0.0364 \\
w R_{2}=0.0966\end{array}$ & $\begin{array}{l}R_{1}=0.0526, \\
w R_{2}=0.1358\end{array}$ & $\begin{array}{l}R_{1}=0.0282 \\
w R_{2}=0.0718\end{array}$ & $\begin{array}{l}R_{1}=0.0340, \\
w R_{2}=0.0953\end{array}$ \\
\hline Final $R$ indexes [all data] & $\begin{array}{l}R_{1}=0.0382 \\
w R_{2}=0.0981\end{array}$ & $\begin{array}{l}R_{1}=0.0583, \\
w R_{2}=0.1451\end{array}$ & $\begin{array}{l}R_{1}=0.0287 \\
w R_{2}=0.0722\end{array}$ & $\begin{array}{l}R_{1}=0.0387 \\
w R_{2}=0.0970\end{array}$ \\
\hline Largest diff. peak/hole/e $\AA^{-3}$ & $0.39 /-0.57$ & $0.81 /-1.07$ & $0.32 /-0.78$ & $0.40 /-0.69$ \\
\hline CCDC no. & $1,577,382$ & $1,577,386$ & $1,577,385$ & $1,577,383$ \\
\hline
\end{tabular}

cations in a monodentate mode to the $\mathrm{N} 1$ nitrogen atom of the aromatic ring (Figs. 4 and 5). The analysis of the valence angles $\mathrm{O} 1 \mathrm{w}-\mathrm{M}-\mathrm{O} 2 \mathrm{w}, \mathrm{O} 1 \mathrm{w}-\mathrm{M}-\mathrm{N} 1$ and $\mathrm{O} 1 \mathrm{w}-\mathrm{M}-$ $\mathrm{N} 1$ does not indicate a distortion of the coordination sphere, since all three angles are close to the right angle. Additionally, the bond lengths: M-N1, M-O1w and M$\mathrm{O} 2 \mathrm{w}$ are nearly equal. Therefore, the coordination sphere can be described as an octahedral. However, in the case of the copper complex, the significant elongation of the $\mathrm{Cu}-$ $\mathrm{O} 2 \mathrm{w}$ bonds is observed (Table 7). This is consistent with the Jahn-Teller effect (JTE) typical for $d^{9}$ electron configuration.
The hydrogen bond patterns for aforementioned pyrimidine-5-carboxylate complexes are marked in Fig. 6 for structures containing cobalt, zinc and manganese cations and in Fig. 7 for the structure of the copper cation separately. There are four intermolecular hydrogen bonds in the crystal packing of the $\mathrm{Co}, \mathrm{Zn}$ and $\mathrm{Mn}$ pyrimidine-5-carboxylate complexes. Three of them are $\mathrm{O}-\mathrm{H} \cdots \mathrm{O}$ type and one is $\mathrm{O}-\mathrm{H}^{\cdots} \mathrm{N}$ type. In case of the $\mathrm{Mn}, \mathrm{Co}$ and $\mathrm{Zn}$ complexes, coordinated water molecules act as a proton donor, while $\mathrm{O} 1$ (uncoordinated), O2 (uncoordinated) and N3 (uncoordinated) atoms play a role of the proton acceptors in hydrogen bonding. However, due to the presence of an additional water molecule in the crystal structure of the $\mathrm{Cu}$
Fig. 4 The molecular structure of the $\mathrm{Mn}(\mathrm{II}), \mathrm{Co}(\mathrm{II})$ and $\mathrm{Zn}$ pyrimidine-5-carboxylates complexes

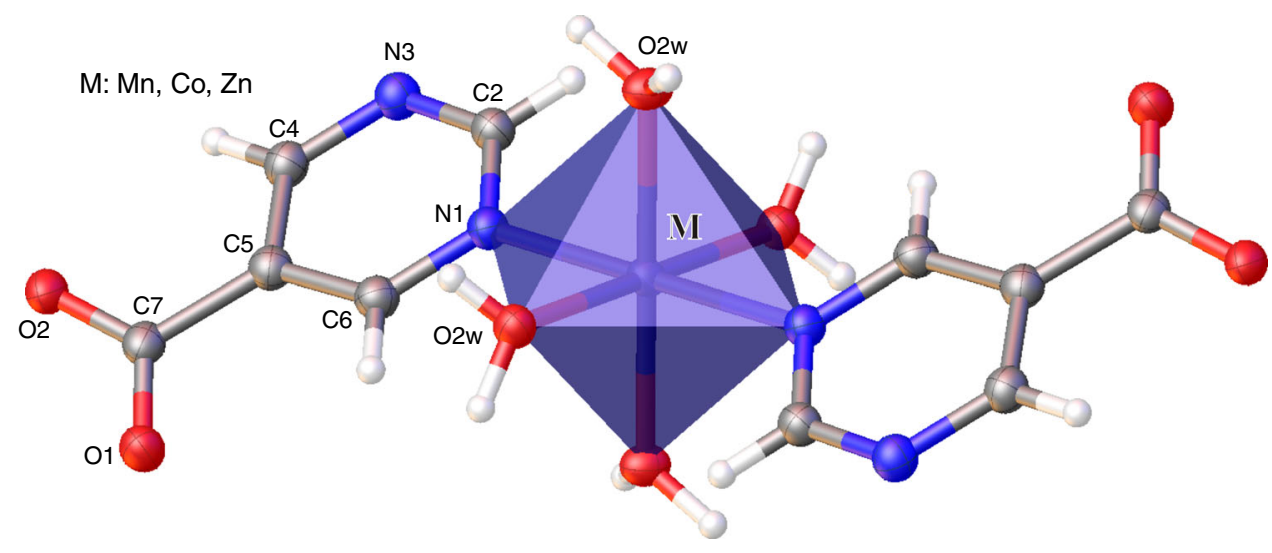


Fig. 5 The molecular structure of the $\mathrm{Cu}$ (II) pyrimidine-5carboxylates complex. The hydrogen bonds of $(x, y$, z) symmetry are presented as a dashed lines

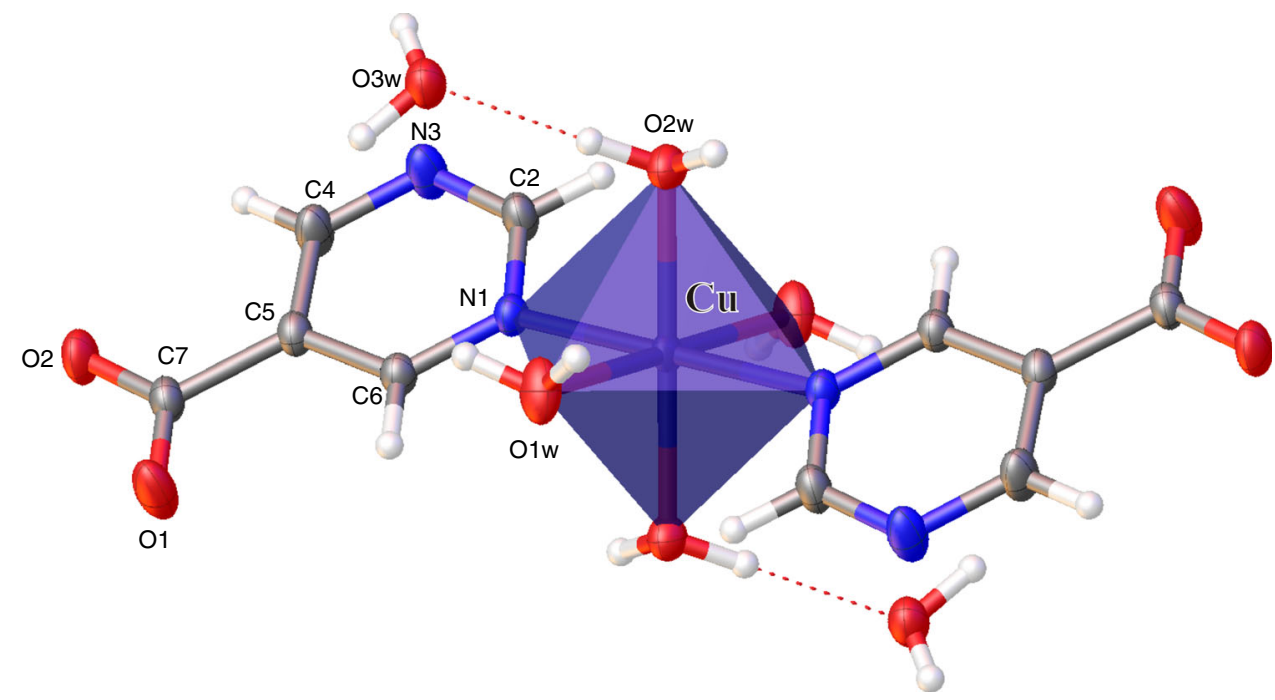

\begin{tabular}{|c|c|c|c|c|}
\hline$\AA{ }^{\circ} \circ$ & Co & $\mathrm{Zn}$ & $\mathrm{Mn}$ & $\mathrm{Cu}$ \\
\hline $\mathrm{N} 1-\mathrm{C} 2$ & $1.344(3)$ & $1.343(2)$ & $1.348(3)$ & $1.338(3)$ \\
\hline $\mathrm{C} 2-\mathrm{N} 3$ & $1.331(3)$ & $1.334(2)$ & $1.333(3)$ & $1.323(3)$ \\
\hline $\mathrm{N} 3-\mathrm{C} 4$ & $1.346(4)$ & $1.345(2)$ & $1.342(3)$ & $1.334(3)$ \\
\hline $\mathrm{C} 4-\mathrm{C} 5$ & $1.388(4)$ & $1.389(2)$ & $1.386(4)$ & $1.380(4)$ \\
\hline C5-C6 & $1.389(3)$ & $1.386(2)$ & $1.387(3)$ & $1.389(3)$ \\
\hline C6-N1 & $1.337(3)$ & $1.345(2)$ & $1.342(3)$ & $1.339(3)$ \\
\hline $\mathrm{C} 5-\mathrm{C} 7$ & $1.511(3)$ & $1.513(2)$ & $1.512(3)$ & $1.509(3)$ \\
\hline C7-O1 & $1.247(3)$ & $1.247(2)$ & $1.246(3)$ & $1.267(3)$ \\
\hline $\mathrm{C} 7-\mathrm{O} 2$ & $1.259(3)$ & $1.264(2)$ & $1.262(3)$ & $1.230(3)$ \\
\hline M-N1 & $2.185(2)$ & $2.194(1)$ & $2.182(3)$ & $2.036(5)$ \\
\hline $\mathrm{M}-\mathrm{O} 1 \mathrm{w}$ & $2.055(1)$ & $2.079(5)$ & $2.076(6)$ & $2.000(8)$ \\
\hline $\mathrm{M}-\mathrm{O} 2 \mathrm{w}$ & $2.077(2)$ & $2.070(8)$ & $2.059(9)$ & $2.345(5)$ \\
\hline $\mathrm{N} 1-\mathrm{C} 2-\mathrm{N} 3$ & $125.7(2)$ & $125.6(1)$ & $125.6(2)$ & $125.8(2)$ \\
\hline $\mathrm{C} 2-\mathrm{N} 3-\mathrm{C} 4$ & $116.7(2)$ & $116.6(1)$ & $116.7(2)$ & $116.0(2)$ \\
\hline N3-C4-C5 & $122.3(2)$ & $122.5(1)$ & $122.6(2)$ & $123.2(2)$ \\
\hline C4-C5-C6 & $116.3(2)$ & $116.2(1)$ & $116.3(2)$ & $116.6(2)$ \\
\hline C5-C6-N1 & $122.4(2)$ & $122.2(1)$ & $122.4(2)$ & $120.8(2)$ \\
\hline $\mathrm{C} 6-\mathrm{N} 1-\mathrm{C} 2$ & $116.7(2)$ & $116.8(1)$ & $116.5(2)$ & $117.6(2)$ \\
\hline C5-C7-O1 & 118.7(2) & $118.8(1)$ & $118.9(2)$ & 118.2(2) \\
\hline $\mathrm{C} 5-\mathrm{C} 7-\mathrm{O} 2$ & $116.2(2)$ & $115.9(1)$ & $116.1(2)$ & $116.3(2)$ \\
\hline $\mathrm{O} 1 \mathrm{~W}-\mathrm{M}-\mathrm{O} 2 \mathrm{~W}$ & $88.4(5)$ & $88.8(4)$ & $88.5(3)$ & $88.1(9)$ \\
\hline $\mathrm{O} 1 \mathrm{~W}-\mathrm{M}-\mathrm{N} 1$ & $89.2(7)$ & $91.3(2)$ & $91.1(5)$ & $91.8(3)$ \\
\hline $\mathrm{O} 2 \mathrm{~W}-\mathrm{M}-\mathrm{N} 2$ & $88.90(8)$ & $90.9(1)$ & $90.8(6)$ & $87.0(6)$ \\
\hline
\end{tabular}

Table 7 Selected geometrical parameters of manganese (II), cobalt (II), zinc and copper (II) pyrimidine-5-carboxylates complexes atoms of the uncoordinated water molecules. The uncoordinated water molecule is a donor in a two additional hydrogen bonds $\mathrm{O} 3 \mathrm{~W}-\mathrm{H} 3 \mathrm{WA} \cdots \mathrm{O} 2$ and $\mathrm{O} 3 \mathrm{~W}-\mathrm{H} 3 \mathrm{WB} \cdots \mathrm{O} 1$, where $\mathrm{O} 1$ and $\mathrm{O} 2$ atoms are the oxygen atoms of different molecules. Selected geometrical parameters of the hydrogen bonds together with the symmetry codes (symm. op. 2) are presented in Table 8. 


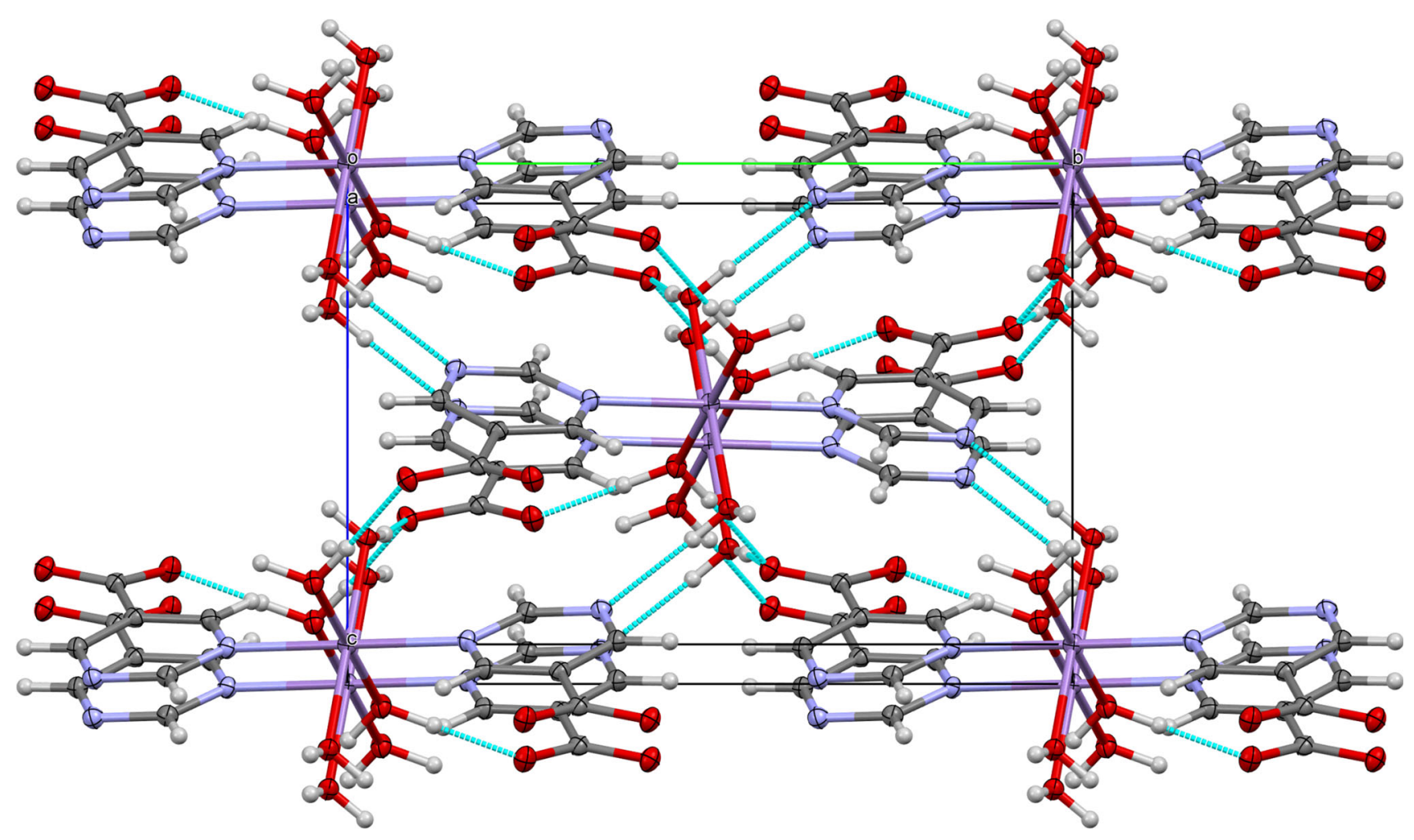

Fig. 6 Crystal structure of the Mn(II), Co(II) and Zn pyrimidine-5-carboxylates complexes. Hydrogen bonds are presented as a dashed lines

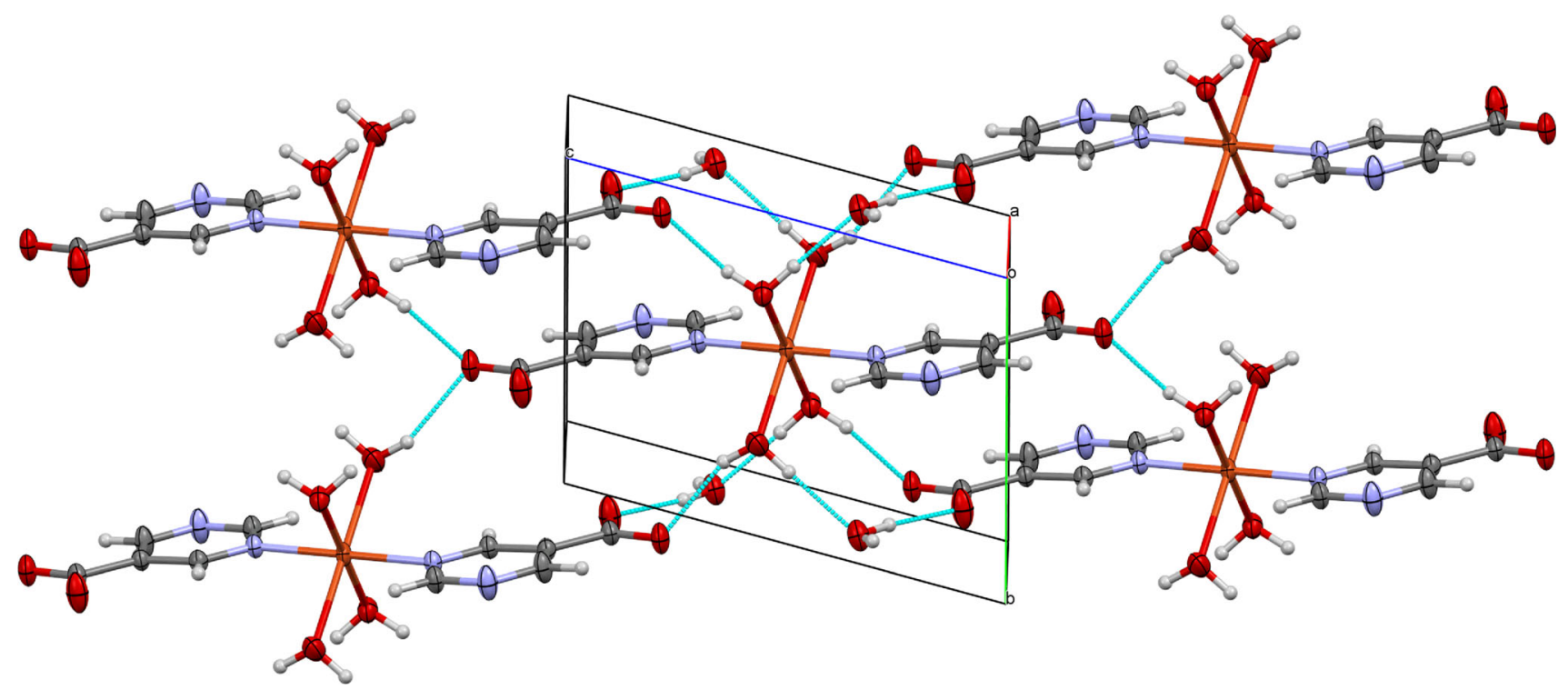

Fig. 7 Crystal structure of the $\mathrm{Cu}(\mathrm{II})$ pyrimidine-5-carboxylates complex. Hydrogen bonds are presented as a dashed lines

\section{Aromaticity}

The aromaticity indexes (Homa and $\mathrm{I}_{6}$ (Bird index) based on the length of bonds in the aromatic ring allow to assess the effect of the metal on the electronic system of the molecule. The values of the indexes of aromaticity have been calculated based on the values of the length of bonds determined experimentally for the $3 \mathrm{~d}$ metal complexes with 5PCA acid. HOMA and I6 indexes for metal complexes have lower values than for ligand. Complexing by the metals (zinc, cobalt, copper, nickel and manganese) causes a decrease in the aromaticity of the pyrimidine ring (Table 9). Due to the lack of geometry data for 2PCA acid, the effect of $3 \mathrm{~d}$ metals on the aromatic system of this 
Table 8 Geometrical parameters of the hydrogen bonds of manganese(II), cobalt(II), zinc and copper(II) pyrimidine-5-carboxylates complexes

\begin{tabular}{lllllllll}
\hline & D & H & A & d(D-H)/A & d(H-A)/A & $\mathrm{d}(\mathrm{D}-\mathrm{A}) / \AA$ & $\mathrm{D}-\mathrm{H}-\mathrm{A} / \mathrm{A}$ & Symm. op. 2 \\
\hline $\mathrm{Mn}$ & O1 W & H1 WA & N3 & $0.82(4)$ & 2.046 & $2.835(3)$ & $163(3)$ & $x, 1 / 2-y,-1 / 2+z$ \\
& O1 W & H1WB & O2 & $0.92(4)$ & 1.756 & $2.670(2)$ & $172(4)$ & $-x,-1 / 2+y, 1 / 2-\mathrm{z}$ \\
& O2 W & H2 WA & O2 & $0.88(4)$ & 1.849 & $2.720(2)$ & $171(4)$ & $-1-x,-1 / 2+y, 1 / 2-\mathrm{z}$ \\
& O2 W & H2WB & O1 & $0.96(4)$ & 1.679 & $2.642(2)$ & $177(4)$ & $-1+x, y, z$ \\
Co & O1 W & H1 WA & O1 & $0.76(4)$ & 1.884 & $2.643(3)$ & $174(4)$ & $1-x,-y,-z$ \\
& O1 W & H1WB & O2 & $0.96(5)$ & 1.781 & $2.725(2)$ & $169(6)$ & $x, 1 / 2-y,-1 / 2+z$ \\
& O2 W & H2 WA & O2 & $0.76(4)$ & 1.921 & $2.669(3)$ & $167(4)$ & $-1+x, 1 / 2-y, 1 / 2+z$ \\
& O2 W & H2WB & N3 & $0.84(5)$ & 2.028 & $2.832(3)$ & $160(5)$ & $-x,-1 / 2+y, 1 / 2-z$ \\
Zn & O1 W & H1 WA & N3 & $0.76(3)$ & 2.104 & $2.8409(18)$ & $164(3)$ & $x, 1.5-y,-1 / 2+z$ \\
& O1 W & H1WB & O2 & $0.79(3)$ & 1.89 & $2.6720(16)$ & $172(3)$ & $-x,-1 / 2+y, 1 / 2-z$ \\
& O2 W & H2 WA & O1 & $0.81(3)$ & 1.837 & $2.6496(16)$ & $175(3)$ & $-1+x, y, z$ \\
& O2 W & H2WB & O2 & $0.87(3)$ & 1.863 & $2.7242(16)$ & $172(3)$ & $1-x,-1 / 2+y, 1 / 2-z$ \\
Cu & O1 W & H1 WA & O1 & 0.87 & 2.114 & $2.799(2)$ & 135.3 & $1-x,-y,-z$ \\
& O1 W & H1WB & O3 W & 0.87 & 1.978 & $2.837(3)$ & 169.3 & $1-x,-y, 1-z$ \\
& O2 W & H2 WA & O1 & 0.87 & 1.921 & $2.713(2)$ & 150.3 & $x, y,-1+z$ \\
& O2 W & H2WB & O3 W & 0.87 & 1.852 & $2.724(2)$ & 178.2 & $x, y, z$ \\
& O3 W & H3 WA & O2 & $0.89(4)$ & 1.815 & $2.699(3)$ & $168(3)$ & $1-x,-y,-z$ \\
& O3 W & H3WB & O1 & $0.81(5)$ & 2.02 & $2.835(3)$ & $176(4)$ & $-x,-y,-z$ \\
\end{tabular}

ligand can not be assessed using aromaticity indices. A comparison of the indexes for the complexes indicates that the 2PCA cobalt and copper complexes have lower aromaticity than the metal complexes of 5PCA, while the zinc complex shows higher aromaticity. The values of the aromatic indexes were also compared for the theoretically modeled structures in B3LYP/LANL2DZ for pyrimidine2-carboxylic and pyrimidine-5-carboxylic acids and their complexes with copper (Fig. 8). The data indicate that copper may stabilize or destabilize the pyrimidine aromatic system depending on the position of the carboxyl group in the ring. In the case of 2PCA, index values indicated an increase in aromaticity after complexing with copper, while in the case of 5PCA, a decrease in the aromaticity system was observed (Table 10).

\section{SOD activity of copper complexes}

SOD activity for the tested compounds was determined by theoretical methods. It is known that $\mathrm{Cu}, \mathrm{Zn}$-SOD dismutase and other compounds trap the superoxide anion in the following reactions:

$$
\begin{aligned}
& \mathrm{E}-\mathrm{Cu}(\mathrm{II})+\mathrm{O}_{2}^{--} \rightarrow \mathrm{E}-\mathrm{Cu}(\mathrm{I})+\mathrm{O}_{2} \\
& \mathrm{E}-\mathrm{Cu}(\mathrm{I})+\mathrm{O}_{2}^{--}+2 \mathrm{H}^{+} \rightarrow \mathrm{E}-\mathrm{Cu}(\mathrm{II})+\mathrm{H}_{2} \mathrm{O}_{2}
\end{aligned}
$$

As a theoretical parameter defining the radical scavenging activity by the studied complexes, the HOMO and LUMO energy values and the EA electron affinity value defined as TEE-Cu(I)-TEE-Cu(II) were selected in which TE E-Cu(I) is the total energy of the complex E-Cu(I) and TEE-Cu(II) with the total energy of the E-Cu(II) complex.

\begin{tabular}{|c|c|c|c|c|c|c|c|c|c|}
\hline \multirow{2}{*}{$\begin{array}{l}\text { Aromaticity } \\
\text { index }\end{array}$} & \multirow{2}{*}{$\begin{array}{l}\text { Pyrimidine-5- } \\
\text { carboxylic }\end{array}$} & \multicolumn{5}{|c|}{ Pyrimidine-5-carboxylate } & \multicolumn{3}{|c|}{ Pyrimidine-2-carboxylate } \\
\hline & & $\begin{array}{l}\text { Manganese } \\
\text { complex }\end{array}$ & $\begin{array}{l}\text { Cobalt } \\
\text { complex }\end{array}$ & $\begin{array}{l}\text { Copper } \\
\text { complex }\end{array}$ & $\begin{array}{l}\text { Zinc } \\
\text { complex }\end{array}$ & $\begin{array}{l}\text { Nickel } \\
\text { complex [19] }\end{array}$ & Cobalt & $\begin{array}{l}\text { Copper } \\
{[18]}\end{array}$ & $\begin{array}{l}\text { Zinc } \\
\text { complex }\end{array}$ \\
\hline HOMA & 0.998 & 0.993 & 0.995 & 0.996 & 0.993 & 0.994 & 0.994 & 0.978 & 0.997 \\
\hline GEO & 0.002 & 0.004 & 0.003 & 0.004 & 0.003 & 0.005 & 0.005 & 0.019 & 0.002 \\
\hline EN & 0.001 & 0.003 & 0.002 & 0.001 & 0.004 & 0.001 & 0.002 & 0.002 & 0.001 \\
\hline $\mathrm{I}_{6}$ & 80.62 & 80.74 & 82.64 & 81.77 & 79.65 & 80.70 & 80.94 & 83.10 & 81.23 \\
\hline
\end{tabular}

Table 9 Aromaticity (HOMA, EN, GEO and $\mathrm{I}_{6}$ ) of pyrimidine-2-carboxylates and pyrimidine-5-carboxylates (experimental structures) 
Fig. 8 The coordination modes of copper complexes with pyrimidinecarboxylic acids calculated in B3LYP/ LANL2DZ

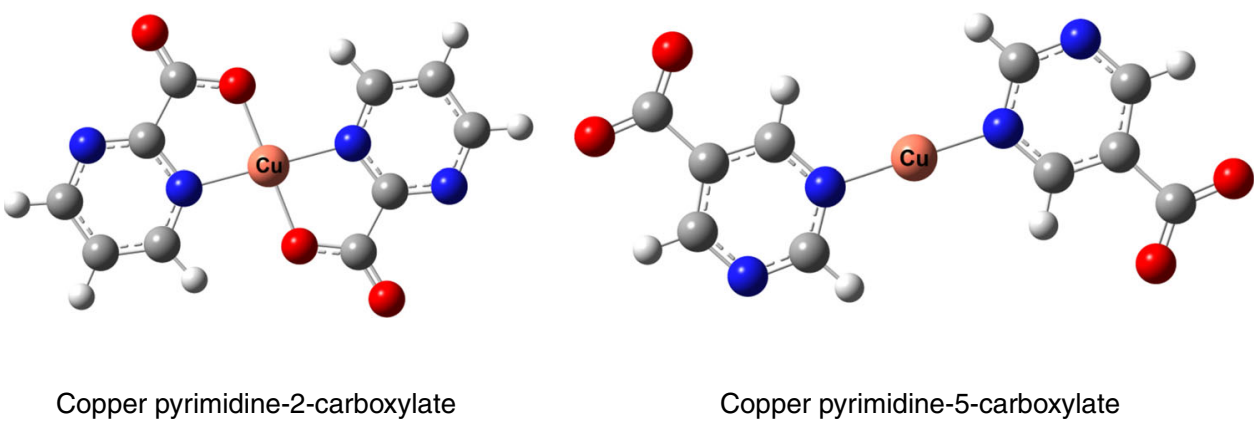

Table 10 Aromaticity (HOMA, EN, GEO and $\mathrm{I}_{6}$ ) of copper pyrimidine-2-carboxylates and copper pyrimidine-5-carboxylates (calculated in B3LYP/LANL2DZ)

\begin{tabular}{lcccc}
\hline Aromaticity index & Pyrimidine-2-carboxylic acid & Copper complex & Pyrimidine-5-carboxylic acid & Copper complex \\
\hline HOMA & 0.936 & 0.940 & 0.915 & 0.912 \\
GEO & 0.002 & 0.005 & 0.005 & 0.010 \\
EN & 0.062 & 0.055 & 0.079 & 0.077 \\
I $_{6}$ & 80.32 & 82.15 & 83.68 & 77.29 \\
\hline
\end{tabular}

The lower the EA value, the higher the electron transfer rate. Electronic affinity (EA) is a good descriptor for characterizing the superoxide radical scavenging activity [48, 49].

The compounds with the lowest EA value have the highest electron transfer capacity, thus giving the highest SOD activity [49]. Calculations of energy values of molecules and HOMO and LUMO molecular orbital have been made for optimized structures of copper complexes with diazines-derived acids. Geometric optimization was performed using the B3LYP density functional method using the LAN2LDZ calculation base.

Figure 9 presents HOMO and LUMO orbitals for copper complexes with pyrimidinecarboxylic acids calculated in B3LYP/LANL2DZ. In Table 11, the values of EA affinity and HOMO and LUMO energy and other parameters characterizing energy values are presented. For comparison, literature data on the energy of the active center of $\mathrm{Cu}, \mathrm{Zn}-\mathrm{SOD}$ enzyme were summarized [49]. EA calculations for copper complexes with diazines-derived acids have shown that the highest SOD activity is exhibited by the pyrimidine-5-carboxylic acid complex (it has the lowest EA energy value of $-108,875 \mathrm{kcal} \mathrm{mol}^{-1}$ ), while the pyrimidine-2-carboxylic acid complex has the lowest activity $-100,021 \mathrm{kcal} \mathrm{mol}^{-1}$. On the basis of the calculated values of EA energy and comparison with the value of this energy for the active center of the enzyme dismutase, it can be concluded that copper complexes with pyrimidine-derived acids behave like superoxide dismutase mimetics. One of the stability criteria for aromatic systems is the energy difference between HOMO and LUMO levels [50].

The higher the HOMO level energy of the $\pi$-reductant compounds, the more easily they can be oxidized, while the $\pi$-deficits compounds they are easier to reduce the easier the lower the energy has the LUMO orbital level.

From the HOMO and LUMO energy calculations for the copper complexes of pyrimidinecarboxylic acids, it appears that the 2PCA copper complex it is easier to reduce than the 5PCA complexes. The hardness of the molecule can be determined based on the HOMO and LUMO energy values. Absolute hardness is defined as follows: [51]:

$\eta=\left(e_{\mathrm{LUMO}}-e_{\mathrm{HOMO}}\right) / 2$

The high value of absolute hardness $\eta$ is a measure of the thermodynamic stability of the system. The value of chemical hardness for copper pyrimidine-5-carboxylate is slightly lower than of copper pyrimidine-2-carboxylate.

\section{IR and Raman spectra}

The pyrimidine-2-carboxylic and pyrimidine-5-carboxylic acids spectra include characteristic bands associated with the oscillation of the carboxyl group and the vibration of the $\mathrm{C}-\mathrm{N}$ bonds of the aromatic ring. The position of these bands in the spectrum of acid depends on the relative position of the carboxyl group and the nitrogen atoms in the aromatic ring. The bands derived from the vibrational stretching $v \mathrm{C}=\mathrm{O}$ in the infrared spectrum of pyrimidine-2carboxylic acid are located at $1743 \mathrm{~cm}^{-1}\left(1738 \mathrm{~cm}^{-1}\right.$ in 
Fig. 9 HOMO and LUMO

orbitals for copper complexes with pyrimidinecarboxylic acids calculated in B3LYP/

LANL2DZ (a: copper pyrimidine-2-carboxylate, $\mathbf{b}$ : copper pyrimidine-5carboxylate)

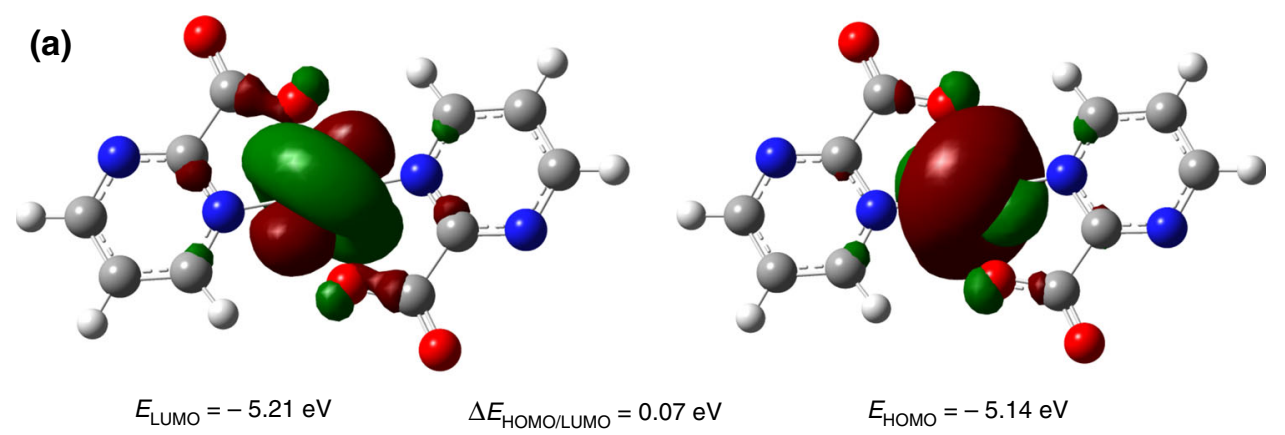

(b)

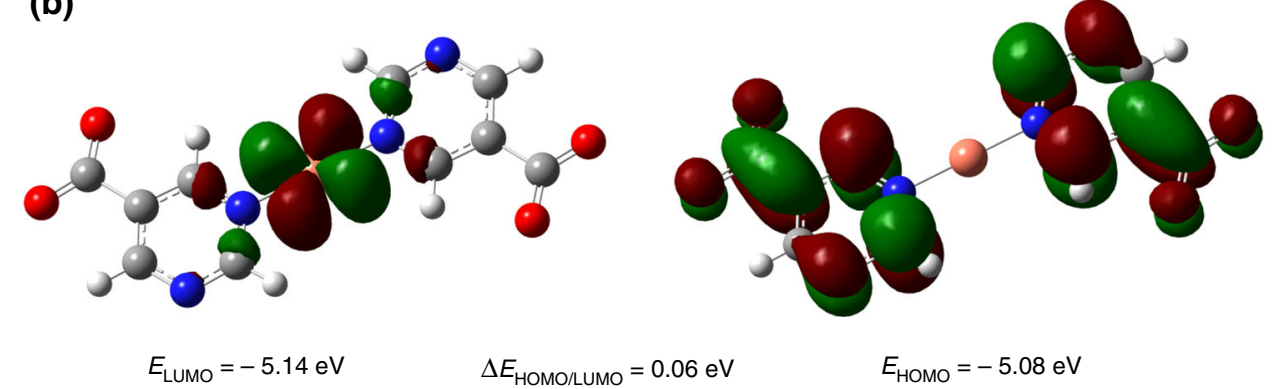

Table 11 Geometrical parameters calculated in B3LYP/LANL2DZ

\begin{tabular}{lcc}
\hline & Copper pyrimidine-2-carboxylate & Copper pyrimidine-5-carboxylate \\
\hline Dipole moment (D) & 0.00003 & 0.0013 \\
$\mathrm{TECu}(\mathrm{II})$ (hartree) & -1100.6524 & -1100.5447 \\
$\mathrm{TECu}(\mathrm{I})$ (hartree) & -1100.8118 & -1100.7182 \\
$\mathrm{EA}\left(\mathrm{kcal} \mathrm{mol}^{-1}\right.$ ) & -100.021 & -108.875 \\
HOMO (Hartree) & -0.19142 & -0.18880 \\
LUMO (Hartree) & -0.18883 & -0.18662 \\
HOMO (eV) & -5.21 & -5.14 \\
LUMO (eV) & -5.14 & -5.08 \\
Energy gap & 0.07 & 0.06 \\
Ionization potential. $I=-\mathrm{E}_{\mathrm{HOMO}}$ & 5.21 & 5.14 \\
Electron Affinity. $A=-\mathrm{E}_{\mathrm{LUMO}}$ & 5.14 & 5.08 \\
Electronegativity. $\chi=\frac{I+A}{2}$ & 5.18 & 5.11 \\
Chemical potential. $\mu=-\frac{I+A}{2}$ & -5.18 & -5.11 \\
Chemical hardness. $\eta=\frac{I-A}{2}$ & 0.035 & 0.030 \\
Chemical softness. $S=\frac{1}{2 \eta}$ & 14.29 & 16.67 \\
Electrophilicity index. $\omega=\frac{\mu^{2}}{2 \eta}$ & 383.32 & 435.20 \\
\hline
\end{tabular}

the IR spectrum of ATR) and $1719 \mathrm{~cm}^{-1}$ and at $1721 \mathrm{~cm}^{-1}$ in the Raman spectrum (Table 12).

In the case of pyrimidine-5-carboxylic acid, the band is located at $1714 \mathrm{~cm}^{-1}$ in the IR spectrum of $\mathrm{KBr}$, $1704 \mathrm{~cm}^{-1}$ IR ATR and at $1708 \mathrm{~cm}^{-1}$ in the Raman spectrum. In the spectra of both acids, the bands originating from the vibrations of the carboxylic group have different positions (Table 13). The close vicinity of the nitrogen atoms of the aromatic ring causes the vibrational numbers of the pyrimidine-2-carboxylic acid carboxyl group to have a higher value than in the pyrimidine-5-carboxylic acid spectrum. In the pyrimidine-5-carboxylic acid spectrum, the band is located at a lower wavenumber. Similar dependencies were noted by comparing the spectra of 


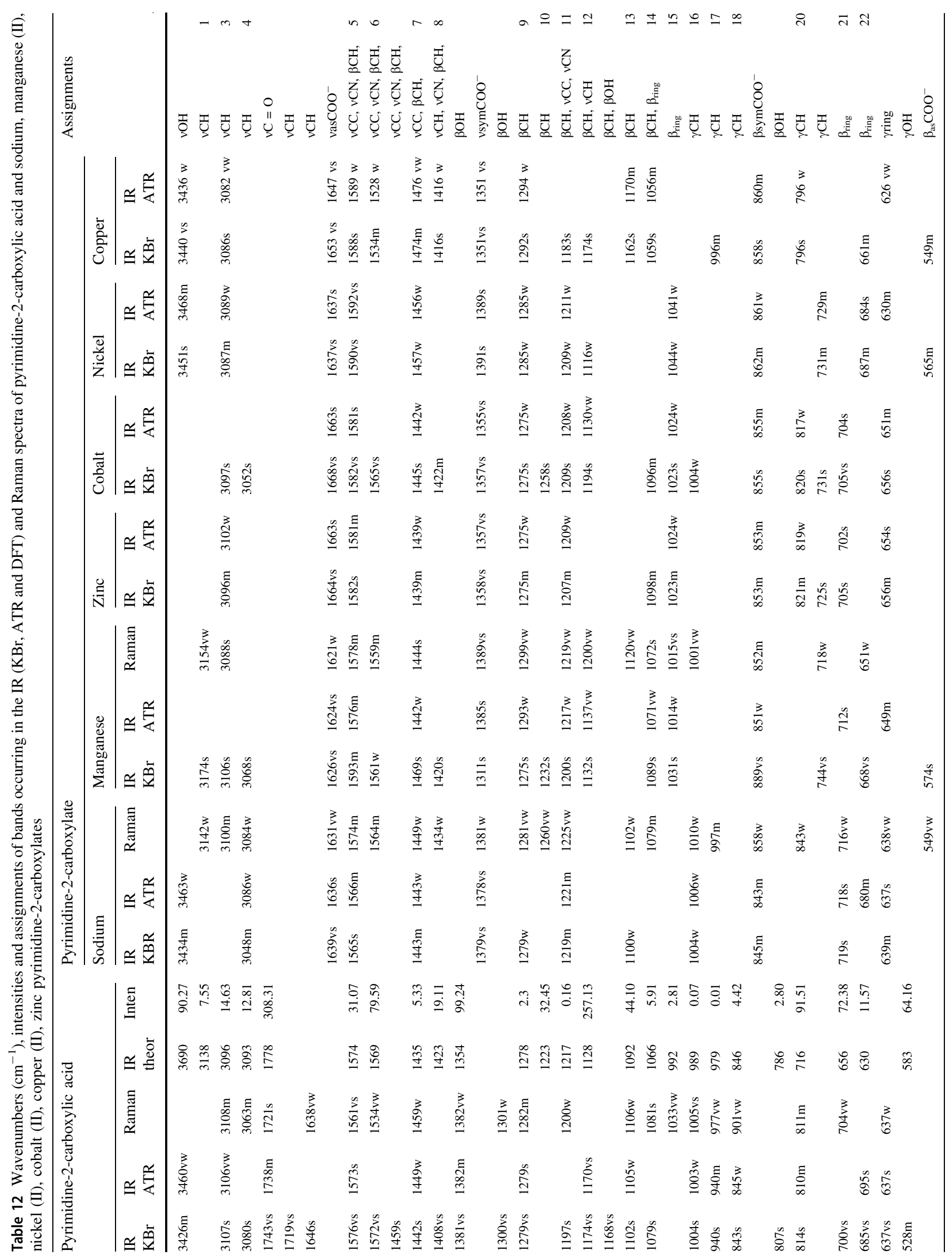




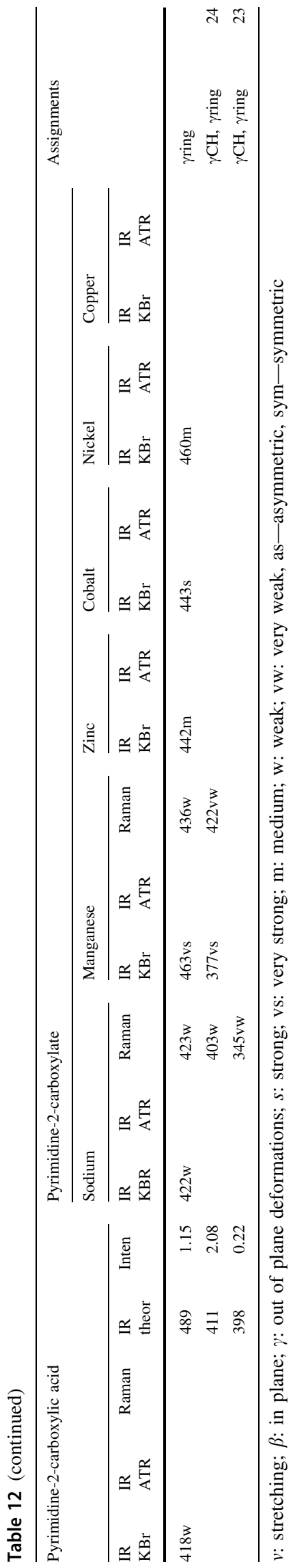

pyridinecarboxylic acids (picolinic, nicotinic and isonicotinic acid) [52]. In the analyzed spectra, differences in the position of bands associated with the vibration of the aromatic system in both acids were observed. Spectral assignments used the normal oscillation of the pyrimidine ring (Fig. 10) measured using B3LYP/6-311++G(d,p).

For example, the band denoted no. 5 is located at $1576 \mathrm{~cm}^{-1}$ in the pyrimidine-2-carboxylic acid IR spectrum and at $1593 \mathrm{~cm}^{-1}$ in the pyrimidine-5-carboxylic acid spectrum.

Also bands 7 and 8 are located at higher values of wave numbers for 5PCA acid than in the 2PCA spectrum $\left(1484 \mathrm{~cm}^{-1}, 1439 \mathrm{~cm}^{-1}\right.$ and $1442 \mathrm{~cm}^{-1}, 1408 \mathrm{~cm}^{-1}$, respectively). In the case of other bands, e.g., 12, 13, 17, there are also significant differences in the position of the bands for each acid. Some of the bands are observed in the pyrimidine-2-carboxylic acid spectrum (e.g., band 14), and they are absent in the pyrimidine-5-carboxylic acid spectrum. Some of the bands are observed in the pyrimidine-5carboxylic acid spectrum (e.g., 10, 15 bands), but they are absent in the pyrimidine-2-carboxylic acid spectrum.

The vibrations of the carboxylate anion are present in the spectra of the pyrimidinecarboxylic acids metal complexes (Figs. 11 and 12). The analysis of position of the asymmetric and symmetrical stretching bands of the carboxylate anion in comparison with position of the bands of carboxylate anion of the sodium salt allows the determination of the metal-ligand coordination mode. Table 14 contains the values of wave numbers of the carboxylate anion vibrations for the 2PCA acid complexes as well as differences in the values of these vibrations. According to Nakamoto, this allows the assessment of the metal-ligand coordination mode [53]. In the case of complexes (Mn, Co, $\mathrm{Cu}, \mathrm{Zn}$ ) of pyrimidine-2-carboxylic acid, the difference in wavenumbers of tensile vibrations of asymmetric and asymmetric carboxylate anions $\left(\Delta v=v_{\mathrm{as}} \mathrm{COO}^{-}-v_{\mathrm{sym}}\right.$ $\mathrm{COO}^{-}$) for $3 \mathrm{~d}$ metal complexes of 2PCA acid is higher than for sodium salts indicates a monodent mode of metalligand coordination by a carboxyl group, which agrees with the X-ray diffraction results for single crystals. Additional metal-ligand binding takes place via the nitrogen atom of the pyrimidine ring, which is observed in changes in the infrared spectra (the disappearance of the tensile bands $v \mathrm{CN}$ in the spectra of the complexes).

In the case of the nickel complex, the difference $\Delta v$ in the spectrum is smaller than in the sodium salt, which suggests a bidentate chelation coordination mode. The mode of metal-ligand coordination by the nitrogen atom without the participation of a carboxylic group is more likely due to the characteristic changes in the bands originating from vibrations of the aromatic system (disappearance of bands in the nickel complex) and the appearance of an unbound carboxylate anion with aligned 


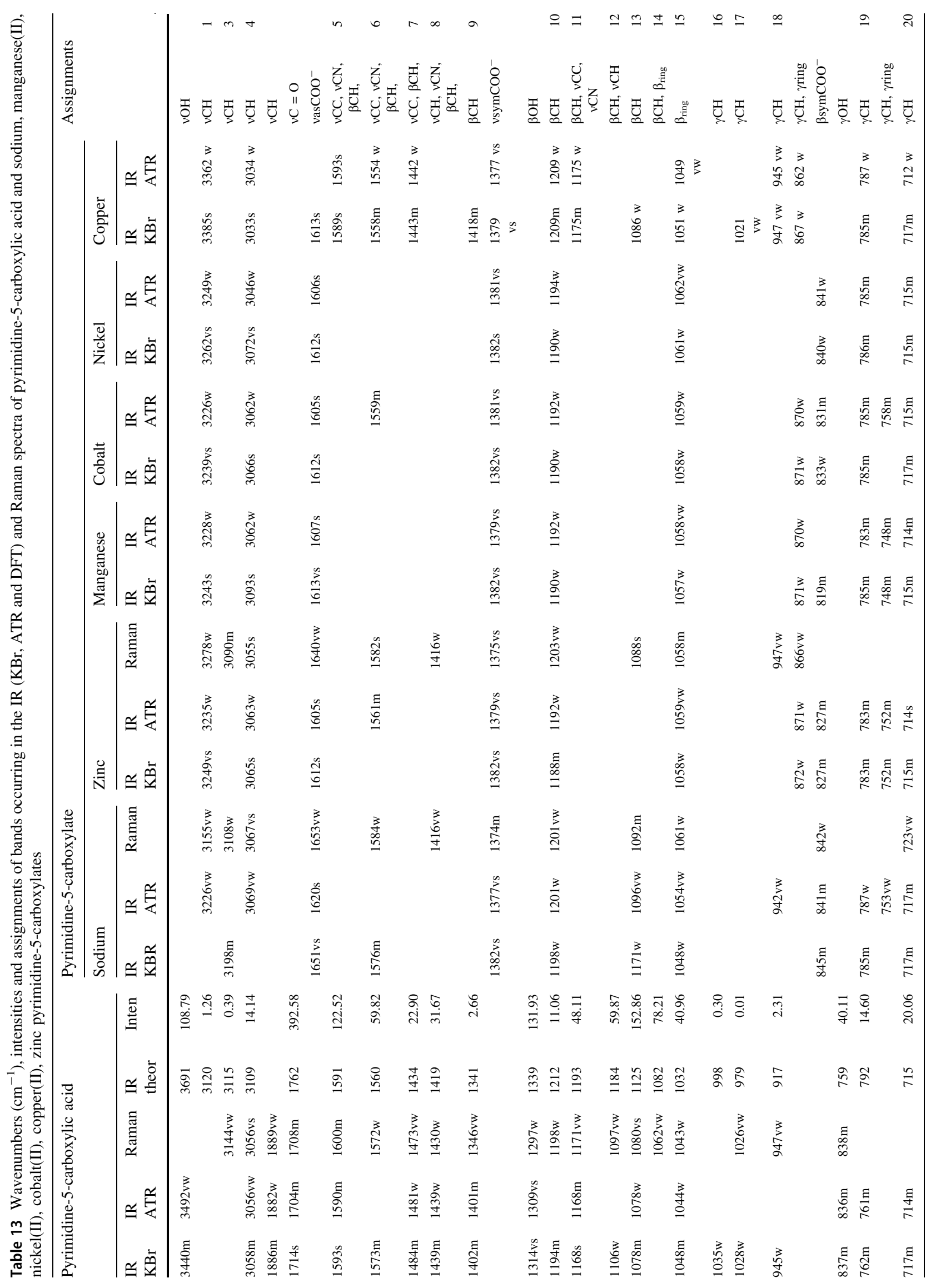




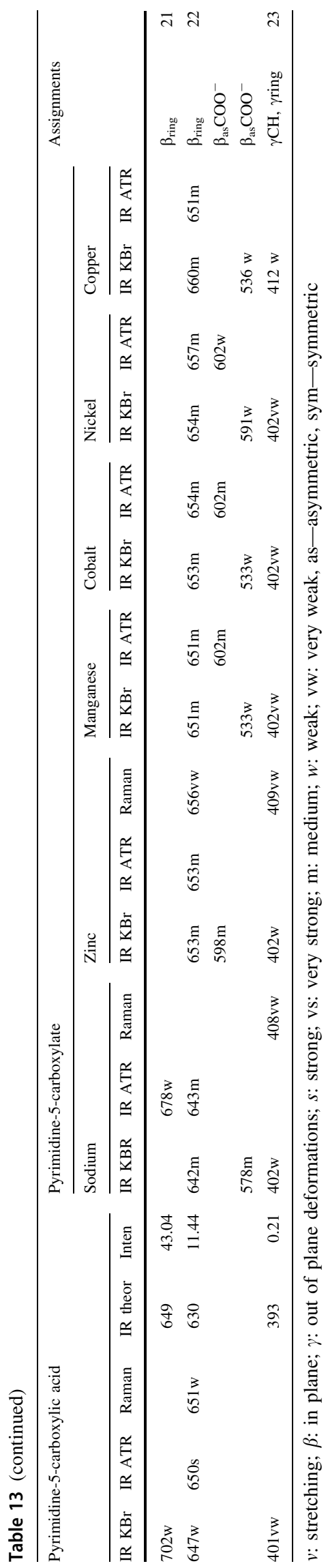

electronic charge on the oxygen atoms in the carboxyl group).

Under the influence of complexing in the acids spectra, changes in the position of many bands are observed, as well as the disappearance or appearance of some bands in complexes with respect to the ligand. Comparative analysis of the position of bands in the spectra of the acid and its complexes allows to assess the influence of the metal on the distribution of the electron charge of the ligand. Our research so far has shown that alkali metals cause disorder of the ligand's aromatic system, while transition metals stabilize the ligand's electronic system [54]. If in the IR and Raman spectra, we observe a decrease in the number, wavenumber and/or intensities of the bands for metal complexes in comparison with the appropriate bands in the spectra of ligands and there is a disorder of the aromatic system. It is caused by a decrease in the force constants of the bonds and polarization of the $\mathrm{C}-\mathrm{C}, \mathrm{C}-\mathrm{N}$ bonds in the ring [54]. By comparing the spectra of sodium salts and pyrimidine-2-carboxylic acid and pyrimidine-5-carboxylic acid, it was observed that sodium causes disorder in the aromatic system in each of the ligands. In the sodium pyrimidine-2-carboxylate spectra, it was observed that for many bands originating from vibrations of the aromatic system and the wavenumber $(3,4,5,6,13)$ are reduced. Many of the bands present in the ligand spectrum disappear in the spectrum of sodium salt $(8,12,14,17,18,20,22)$. Some of the bands do not change $(7,9,10,16)$, and only for some bands, the wavenumbers increase in the spectrum of the sodium salt with respect to the ligand $(11,21,23)$. Similar observations have been made for 5PCA acid and its sodium salt.

In the spectrum of sodium salt, a number of bands present in the spectrum of acid disappear. These are bands marked with $4,5,7,8,9,11,12,17,18,21)$. Some of the bands are shifted toward the lower values of wave numbers in the spectrum of sodium salt $(13,22)$. An increase in the value of wave numbers for vibration bands $(6,10,19,23)$ in the spectrum of sodium salt with respect to the spectrum of the acid was also observed. The analysis showed that the atom of the lithium destabilizes the pyrimidine-5-carboxylic acid electron system to a greater extent than the pyrimidine-2-carboxylic acid.

The position of heteroatoms relative to the carboxyl group is important here. Similarly, it was observed in the case of the influence of alkaline metals on the electronic system of pyridinecarboxylic acids [55]. Transition metals, as shown in previous studies, stabilize the ligand electron system. In the IR and Raman spectra, this is observed in the form of an increase in wave numbers of bands originating from vibrations of the aromatic system of complexes with respect to the ligand. In the spectra of transition metal of pyrimidine-2-carboxylic acid complexes, an increase in 
wave numbers of many bands originating from the vibrations of the aromatic system was observed $(5,7,8,11,13$, $20,21)$. There are also vibration-derived bands that were absent in the spectrum of the ligand (e.g., band No. 15). For some of the bands, decreasing of the wavenumber value in the complex spectrum with respect to the ligand or disappearance of the bands $(6,9,12,16)$ was observed. This indicates an increase in the aromaticity of the 2PCA acid system under the influence of complexation. In the spectra of pyrimidine-5-carboxylic acid metal complexes, greater changes were observed with respect to the ligand than in the spectra of the pyrimidine-5-carboxylic acid complexes. Decreased values of wave numbers or disappearance of bands derived from vibrations of the pyrimidine carboxylic acid ring were observed. These are bands marked with 5, 6, $7,8,9,12,13,14$. An increase in wavenumbers was observed only for some bands $(10,11,15)$. A comparative analysis of the spectra of pyrimidine carboxylate complexes and pyrimidinecarboxylic acids has shown that
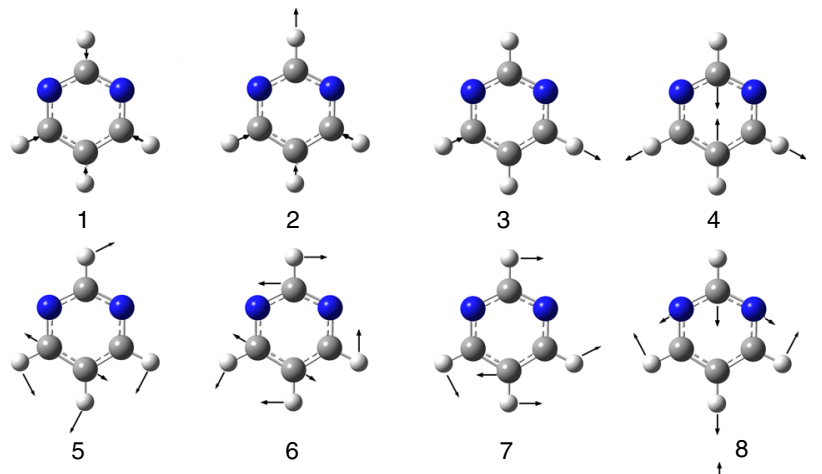

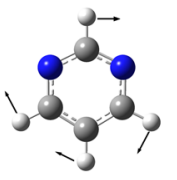

9
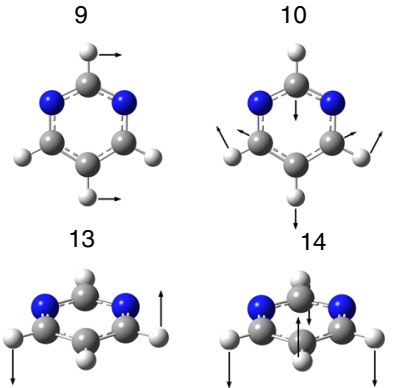

17
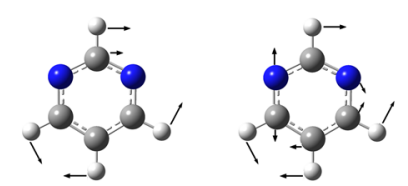

11
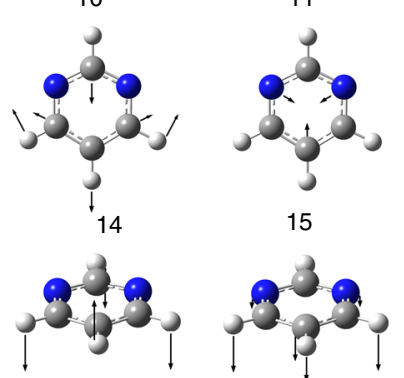

18

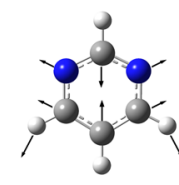

21
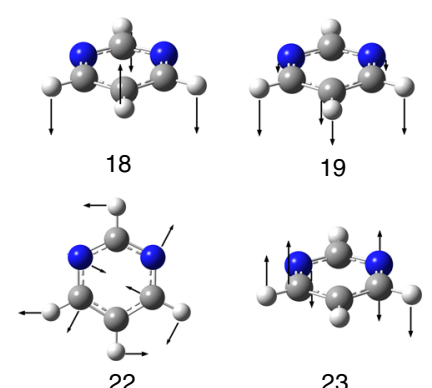

19

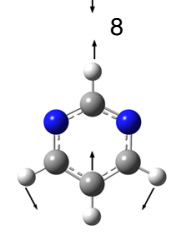

12

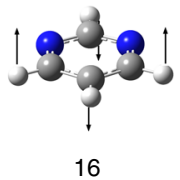

16

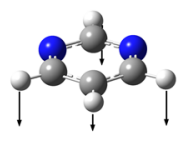

20

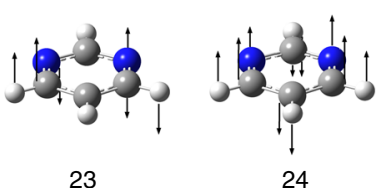

Fig. 10 Normal modes of pyrimidine ring calculated in DFT/B3LYP/ $6-311++(d, p)$ transition $3 \mathrm{~d}$ metals have a greater impact on the $2 \mathrm{PCA}$ acid aromatics system than 5PCA acid. In the case of 2PCA, the transition metals attached via the carboxyl group and the nitrogen atom of the aromatic ring stabilize the electron system, whereas in the case of pyrimidine-5-carboxylic acid complexes, a disorder of the aromatic ligand system is observed. Direct attachment of the metal to the aromatic pyrimidine ring causes an increase in the disturbance of the aromatic system.

\section{Thermal analysis}

Different methods of thermal analysis (TG-DSC, TGFTIR) were used to determine thermal behavior of two series of metal(II) complexes during heating in air and nitrogen atmospheres. Thermal analysis methods allow to demonstrate that the same metal ions with the isomers of pyrimidinecarboxylic acid give complexes with a different number of solvent molecules. The pyrimidine-2-carboxylate complexes contain in the structure a smaller number of water molecules compared to the corresponding complexes with pyrimidine-5-carboxylic acid.

Thermal decomposition of the investigated complexes in air atmosphere proceeds in two main stages connected with dehydration and decomposition/burning processes (Tables 15, 16, Figs. 13-17).

Manganese(II) pyrimidine-2-carboxylate $\left(\mathrm{MnL}_{1}\right)$ as an anhydrous complex exhibits high thermal stability up to about $250{ }^{\circ} \mathrm{C}$, while manganese(II) pyrimidine-5-carboxylate tetrahydrate $\left(\mathrm{MnL}_{2} \cdot 4 \mathrm{H}_{2} \mathrm{O}\right)$ is stable to $110{ }^{\circ} \mathrm{C}$ (Fig. 13). Further heating leads to the one-stage removal of all four water molecules associated with $18.85 \%$ mass loss in the temperature range $110-140{ }^{\circ} \mathrm{C}$ accompanied by a strong endothermic effect at $122{ }^{\circ} \mathrm{C}$ observed on the DSC curve. The corresponding molar enthalpy of dehydration process is equal to $153.5 \mathrm{~kJ} \mathrm{~mol}^{-1}$. An anhydrous form of manganese(II) pyrimidine-5-carboxylate is thermally stable up to about $350{ }^{\circ} \mathrm{C}$. Further heating of both manganese(II) complexes results in distinct mass losses observed on the TG curves connected with one-stage decomposition and combustion of organic ligands. Very strong exothermic effects appear on the DSC curves. Manganese(III) oxide is the final decomposition product formed at about $470-480{ }^{\circ} \mathrm{C}$. During heating up to about $940{ }^{\circ} \mathrm{C}, \mathrm{Mn}_{2} \mathrm{O}_{3}$ transforms into $\mathrm{Mn}_{3} \mathrm{O}_{4}[56,57]$.

The first mass losses on the TG curves of cobalt complexes $\mathrm{CoL}_{1} \cdot 2 \mathrm{H}_{2} \mathrm{O}$ and $\mathrm{CoL}_{2} \cdot 4 \mathrm{H}_{2} \mathrm{O}$ are a result of the dehydration process (Fig. 14). The release of water molecules in the $\mathrm{CoL}_{1} \cdot 2 \mathrm{H}_{2} \mathrm{O}$ complex takes place in the temperature range $150-220^{\circ} \mathrm{C}$. The other complex is less stable, and loss of solvent molecules is observed at lower temperature $123-205^{\circ} \mathrm{C}$. The shapes of the DSC curves of both complexes $\mathrm{CoL}_{1} \cdot 2 \mathrm{H}_{2} \mathrm{O}$ and $\mathrm{CoL}_{2} \cdot 4 \mathrm{H}_{2} \mathrm{O}$ indicate that 
Fig. 11 IR spectra of pyrimidine-2-carboxylates in the range from 500 to $2000 \mathrm{~cm}^{-1}$ (from above: pyrimidine-2-carboxylic acid, sodium complex, manganese(II) complex, cobalt(II) complex, nickel(II) complex, copper(II) complex and zinc complex)

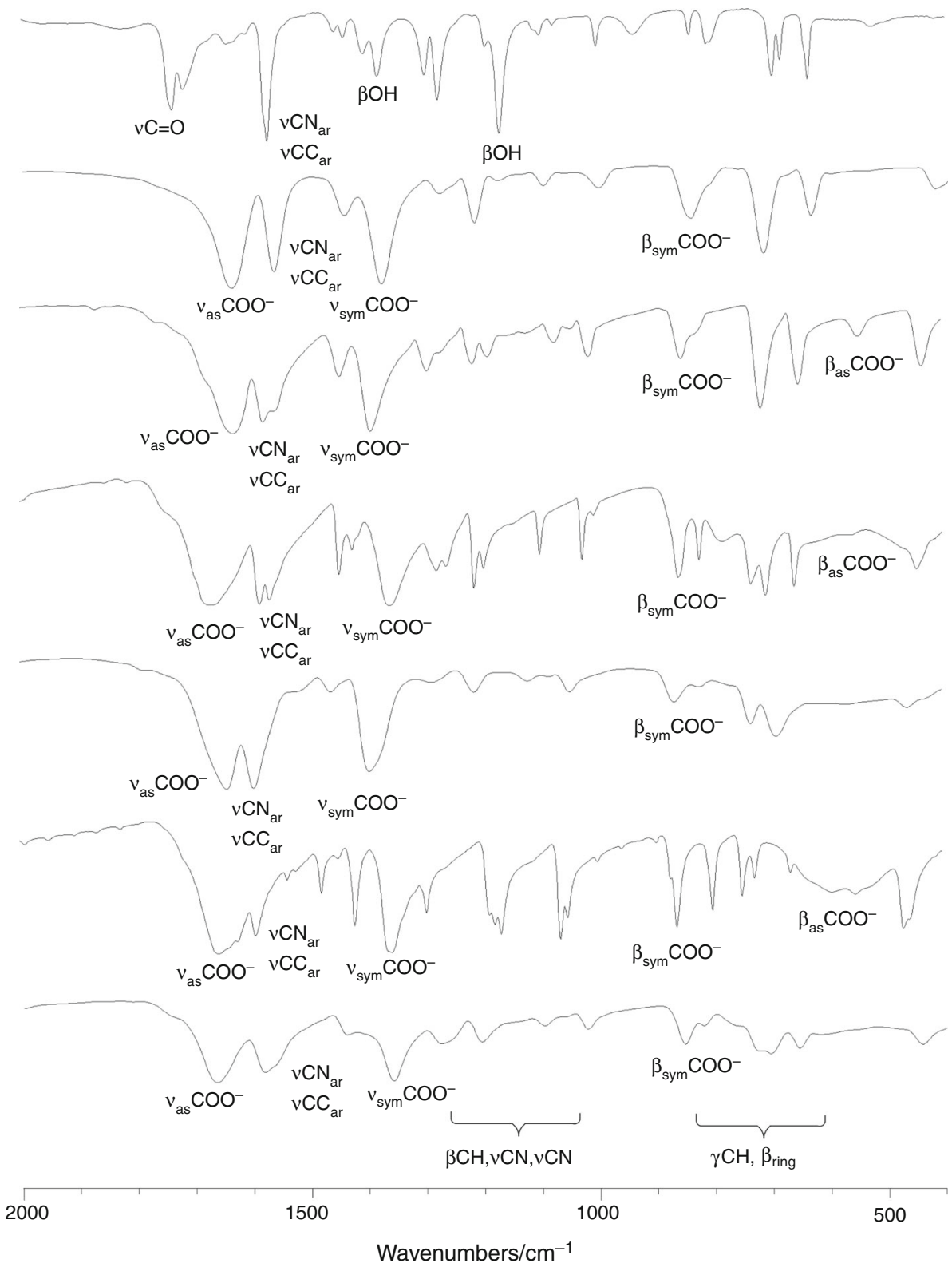

removal of water molecules occurs in overlapping stages with the overall molar dehydration enthalpy values of $78.0 \mathrm{~kJ} \mathrm{~mol}^{-1}$ and $177.9 \mathrm{~kJ} \mathrm{~mol}^{-1}$, respectively. The anhydrous complexes $\mathrm{CoL}_{1}$ and $\mathrm{CoL}_{2}$ are stable in the narrow temperature ranges $220-307$ and $205-260{ }^{\circ} \mathrm{C}$, respectively. At a higher temperature, two mass losses appear on the TG curves as a result of the decomposition and burning of the anhydrous form of complexes. These stages are accompanied by very strong exothermic effects. As the final solid product of thermal decomposition, $\mathrm{Co}_{3} \mathrm{O}_{4}$ is formed. Further heating of such compound leads to the transformation into the $\mathrm{CoO}$ at about $940{ }^{\circ} \mathrm{C}[58,59]$.

The nickel complexes $\mathrm{NiL}_{1} \cdot 2 \mathrm{H}_{2} \mathrm{O}$ and $\mathrm{NiL}_{2} \cdot 4 \mathrm{H}_{2} \mathrm{O}$ exhibit thermal stability up to 164 and $132{ }^{\circ} \mathrm{C}$, respectively (Fig. 15). During heating of nickel(II) pyrimidine-2- carboxylate dihydrate, the removal of both water molecules occurs in the temperature range $164-258{ }^{\circ} \mathrm{C}$. The first mass loss connected with the dehydration process is $11.58 \%$ (calc. 10.57\%). As can be deduced from the shape of the DSC curve, this process probably proceeds in two stages (temperatures of the endothermic peaks are $201{ }^{\circ} \mathrm{C}$ and $229^{\circ} \mathrm{C}$ ) with the overall enthalpy of $83.6 \mathrm{~kJ} \mathrm{~mol}^{-1}$. Nickel(II) pyrimidine-5-carboxylate tetrahydrate loses all water molecules in one stage in the temperature range 132-208 ${ }^{\circ} \mathrm{C}$ with the corresponding molar dehydration enthalpy value of $192.3 \mathrm{~kJ} \mathrm{~mol}^{-1}$ (the maximum of the endothermic peak at $200{ }^{\circ} \mathrm{C}$ ). Anhydrous compounds are stable in narrow temperature ranges and heating leads to the two-stage decomposition connected with burning of the organic ligand. Very strong exothermic effects can be 
Fig. 12 IR spectra of pyrimidine-5-carboxylates in the range from 500 to $2000 \mathrm{~cm}^{-1}$ (from above: pyrimidine-5-carboxylic acid, sodium complex, manganese(II) complex, cobalt(II) complex, nickel(II) complex, copper(II) complex and zinc complex)

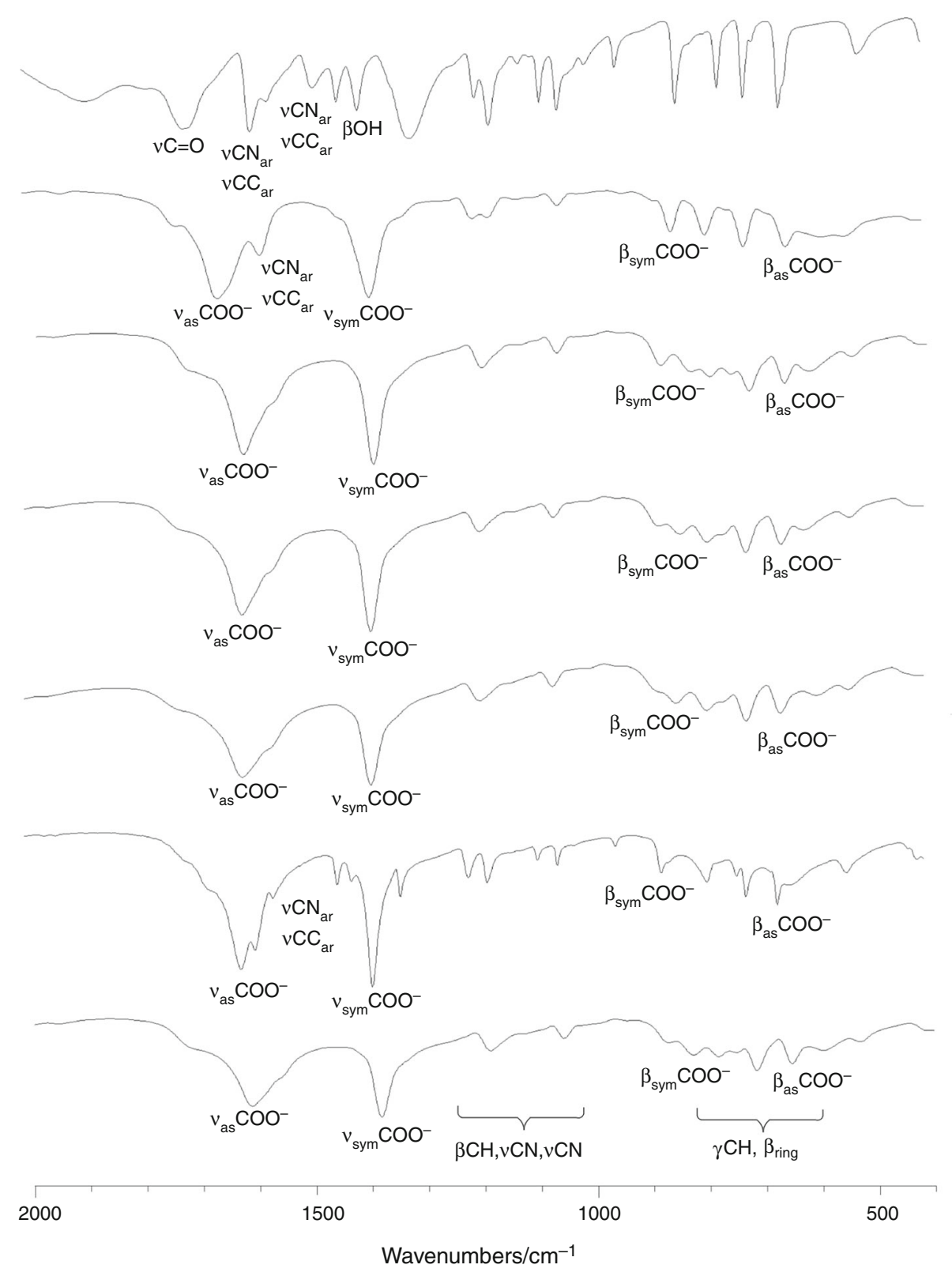

Table 14 Spectral parameters (vibrations stretching the carboxylate anion) from the IR spectra of pyrimidine-2-carboxylates and proposed type of coordination the metal to carboxylic group of the ligand

\begin{tabular}{lllll}
\hline Compound & $\begin{array}{l}v_{\text {asym }}\left(\mathrm{COO}^{-}\right) \\
\text {Wavenumber/cm }\end{array}$ & $\begin{array}{l}v_{\text {sym }}\left(\mathrm{COO}^{-}\right) \\
\text {Wavenumber/cm }\end{array}$ & $\begin{array}{l}\Delta v^{\mathrm{a}} \\
\text { Wavenumber/cm }\end{array}$ & Proposed coordination \\
\hline Sodium salt & 1639 & 1379 & 260 & Monodentate \\
Manganese complex & 1626 & 1311 & 315 & Monodentate \\
Cobalt complex & 1668 & 1357 & 311 & Bidentate chelation \\
Nickel complex & 1637 & 1391 & 246 & Monodentate \\
Copper complex & 1653 & 1351 & 302 & Monodentate \\
Zinc complex & 1664 & 1358 & 306 & \\
\hline
\end{tabular}

${ }^{\mathrm{a}} \Delta v=v_{\mathrm{asym}}\left(\mathrm{COO}^{-}\right)-v_{\mathrm{sym}}\left(\mathrm{COO}^{-}\right)$ 
observed on the DSC curves. Nickel(II) oxide is formed at about $480{ }^{\circ} \mathrm{C}$ as the final solid product of thermal decomposition nickel complexes [60].

The copper(II) compound with pyrimidine-2-carboxylic acid as a anhydrous complex displays great thermal stability. Two-stage decomposition occurs in the temperature range of $260-390{ }^{\circ} \mathrm{C}$. As the final solid product of decomposition, copper(II) oxide is formed. Copper(II) pyrimidine-5-carboxylate hexahydrate is stable to $80{ }^{\circ} \mathrm{C}$. During further heating, the dehydration process occurs in two hardly separated stages. Mass losses of $24.30 \%$ and $2 \%$ observed on the TG curve are associated with the removal of 5.5 and 0.5 water molecules. The first stage of dehydration is accompanied by a very strong endothermic effect with the molar enthalpy of dehydration equal to $200.7 \mathrm{~kJ} \mathrm{~mol}^{-1}$ (temperature of the peak maximum is $95.6^{\circ} \mathrm{C}$ ). The other endothermic effect was recorded at $150{ }^{\circ} \mathrm{C}$. The dehydrated form of complex is stable to $245{ }^{\circ} \mathrm{C}$. Next, the two-step decomposition takes place in the range $286-384{ }^{\circ} \mathrm{C}$ (Fig. 16). Also, $\mathrm{CuO}$ is formed as stable solid residue $[58,61]$.

The zinc complexes $\mathrm{ZnL}_{1} \cdot 2 \mathrm{H}_{2} \mathrm{O}$ and $\mathrm{ZnL}_{2} \cdot 4 \mathrm{H}_{2} \mathrm{O}$ are thermally stable up to 110 and $98{ }^{\circ} \mathrm{C}$, respectively (Fig. 17). At higher temperature, mass losses on the TG curves are observed due to the dehydration process. As can be concluded from the TG and DSC curves of the $\mathrm{ZnL}_{1}$ $2 \mathrm{H}_{2} \mathrm{O}$ complex, release of water molecules takes place in two hardly distinguishable stages. The mass loss of $10.97 \%$ is observed in the temperature range $110-190{ }^{\circ} \mathrm{C}$. The dehydration process proceeds with the two overlapping endothermic effects with the maxima at $144{ }^{\circ} \mathrm{C}$ and $156^{\circ} \mathrm{C}$ and total molar dehydration enthalpy of $83.6 \mathrm{~kJ} \mathrm{~mol}^{-1}$. In the other zinc complex, four water molecules are released in one stage in the narrow temperature range $110-140{ }^{\circ} \mathrm{C}$. This process is accompanied by a very strong endothermic effect with the molar dehydration enthalpy $174.8 \mathrm{~kJ} \mathrm{~mol}^{-1}$. The dehydration process resulted in the formation of anhydrous compounds which are stable in the relatively wide temperature ranges: $190-370{ }^{\circ} \mathrm{C}$ and $152-316^{\circ} \mathrm{C}$. Similarly to the above-described compounds, further heating leads to the two-stage decomposition resulting from degradation and burning of anhydrous form of complex. Zinc oxide is formed as a final solid product of complexes decomposition [58,60].

\section{TG-FTIR analysis}

Volatile products of thermal decomposition of the $\mathrm{CoL}_{1-}$ $2 \mathrm{H}_{2} \mathrm{O}$ and $\mathrm{CoL}_{2} \cdot 4 \mathrm{H}_{2} \mathrm{O}$ complexes were investigated by the coupled TG-FTIR method as representatives of two series of investigated complexes. The infrared spectra of gaseous products released during complexes heating in nitrogen atmosphere are given in Fig. 18. The $\mathrm{CoL}_{1} \cdot 2 \mathrm{H}_{2} \mathrm{O}$ complex is stable in the nitrogen temperature to $178{ }^{\circ} \mathrm{C}$. Next, in the temperature range $180-240{ }^{\circ} \mathrm{C}$, water molecules are evolved. The FTIR spectra exhibit characteristic bands in the wavenumber ranges $4000-3400 \mathrm{~cm}^{-1}$ and $1800-1200 \mathrm{~cm}^{-1}$ corresponding to the stretching and deformation vibrations of water molecules [57]. As shown in Fig. 18, the dehydrated form of the complex is stable up to $330^{\circ} \mathrm{C}$. At higher temperature, carbon dioxide molecules are released. The FTIR spectra show very diagnostic characteristic bands in the region $2359-2310 \mathrm{~cm}^{-1}$ and that at $669 \mathrm{~cm}^{-1}$ derived from the stretching and deformation vibrations of carbon dioxide (Fig. 18). Above $450{ }^{\circ} \mathrm{C}$ besides the bands from the carbon dioxide molecules, also a double band with the maxima at 2182 and $2094 \mathrm{~cm}^{-1}$ is observed due to evolved carbon monoxide [62]. Moreover, along with carbon oxides weak bands derived from the ammonia and pyrimidine molecules are observed. These gases give the most intense bands at $440-500{ }^{\circ} \mathrm{C}$. Identification of pyrimidine molecules can be made based on the bands in the region $3100-3000 \mathrm{~cm}^{-1}$ which can be assigned to the stretching vibrations of $\mathrm{CH}$ groups. The bands recorded at $1569,1540 \mathrm{~cm}^{-1}$ and those at $1436,1339 \mathrm{~cm}^{-1}$ can be ascribed to the stretching

Table 15 Results of thermal decomposition of $\mathrm{Ni}(\mathrm{II}), \mathrm{Co}(\mathrm{II}), \mathrm{Cu}(\mathrm{II}), \mathrm{Zn}(\mathrm{II})$ and $\mathrm{Mn}$ (II) complexes with pyrimidine-2-carboxylic acid in air

\begin{tabular}{|c|c|c|c|c|c|c|c|c|}
\hline \multirow[t]{2}{*}{ Complex } & \multirow[t]{2}{*}{$\Delta T_{1} /{ }^{\circ} \mathrm{C}$} & \multirow[t]{2}{*}{$\Delta H / \mathrm{kJ} \mathrm{mol}^{-1}\left(T_{\text {peak }} /{ }^{\circ} \mathrm{C}\right)$} & \multicolumn{2}{|c|}{ Mass loss $/ \%$} & \multirow[t]{2}{*}{$\Delta T_{2} /{ }^{\circ} \mathrm{C}$} & \multicolumn{2}{|c|}{ Mass loss/\% } & \multirow[t]{2}{*}{ Residue } \\
\hline & & & Found & Calc. & & Found & Calc. & \\
\hline $\mathrm{Co}(2 \mathrm{PCA})_{2} \cdot 2 \mathrm{H}_{2} \mathrm{O}$ & $150-220$ & $78.0(183,198)$ & 12.39 & 10.55 & $307-480 *$ & 78.60 & 77.07 & $\mathrm{Co}_{3} \mathrm{O}_{4}$ \\
\hline $\mathrm{Ni}(2 \mathrm{PCA})_{2} \cdot 2 \mathrm{H}_{2} \mathrm{O}$ & $164-258$ & $83.6(201,229)(201,229)$ & 11.58 & 10.57 & $320-480$ & 78.72 & 78.08 & $\mathrm{NiO}$ \\
\hline $\mathrm{Zn}(2 \mathrm{PCA})_{2} \cdot 2 \mathrm{H}_{2} \mathrm{O}$ & $110-190$ & $83.6(144,156)$ & 10.97 & 10.36 & $370-530$ & 77.67 & 76.56 & $\mathrm{ZnO}$ \\
\hline $\mathrm{Mn}(2 \mathrm{PCA})_{2}$ & - & & - & - & $250-489 * *$ & 74.15 & 73.78 & $\mathrm{Mn}_{2} \mathrm{O}_{3}$ \\
\hline $\mathrm{Cu}(2 \mathrm{PCA})_{2}$ & - & & - & - & $260-390$ & 74.57 & 74.30 & $\mathrm{CuO}$ \\
\hline
\end{tabular}

$2 \mathrm{PCA}-\mathrm{C}_{5} \mathrm{H}_{3} \mathrm{~N}_{2} \mathrm{O}_{2}$ (pyrimidine-2-carboxylate); $\Delta T_{1}$-temperature range of dehydration; $\Delta T_{2}$-temperature range of degradation of anhydrous complex to suitable oxide; *-further transformation of $\mathrm{Co}_{3} \mathrm{O}_{4}$ oxide into $\mathrm{CoO}$ oxide is observed; **-further transformation of $\mathrm{Mn}_{2} \mathrm{O}_{3}$ oxide into $\mathrm{Mn}_{3} \mathrm{O}_{4}$ oxide is observed 
Table 16 Results of thermal decomposition of Ni(II), Co(II), $\mathrm{Cu}(\mathrm{II}), \mathrm{Zn}(\mathrm{II})$ and $\mathrm{Mn}(\mathrm{II})$ complexes with pyrimidine-5-carboxylic acid in air

\begin{tabular}{|c|c|c|c|c|c|c|c|c|}
\hline \multirow[t]{2}{*}{ Complex } & \multirow[t]{2}{*}{$\Delta T_{1} /{ }^{\circ} \mathrm{C}$} & \multirow[t]{2}{*}{$\left(\Delta H / \mathrm{kJ} \mathrm{mol}^{-1}\left(T_{\text {peak }} /{ }^{\circ} \mathrm{C}\right)\right.$} & \multicolumn{2}{|c|}{ Mass loss $/ \%$} & \multirow[t]{2}{*}{$\Delta T_{2} /{ }^{\circ} \mathrm{C}$} & \multicolumn{2}{|c|}{ Mass loss/\% } & \multirow[t]{2}{*}{ Residue } \\
\hline & & & Found & Calc. & & Found & Calc. & \\
\hline $\mathrm{Co}(5 \mathrm{PCA})_{2} \cdot 4 \mathrm{H}_{2} \mathrm{O}$ & $123-205$ & $177.9(183)$ & 19.95 & 19.10 & $260-449 *$ & 79.73 & 78.71 & $\mathrm{Co}_{3} \mathrm{O}_{4}$ \\
\hline $\mathrm{Ni}(5 \mathrm{PCA})_{2} \cdot 4 \mathrm{H}_{2} \mathrm{O}$ & $132-208$ & $192.3(200)$ & 20.30 & 19.11 & $300-480$ & 79.96 & 80.17 & $\mathrm{NiO}$ \\
\hline $\mathrm{Zn}(5 \mathrm{PCA})_{2} \cdot 4 \mathrm{H}_{2} \mathrm{O}$ & $98-152$ & $174.8(133)$ & 19.23 & 18.78 & $316-572$ & 82.09 & 78.76 & $\mathrm{ZnO}$ \\
\hline $\mathrm{Mn}(5 \mathrm{PCA})_{2} \cdot 4 \mathrm{H}_{2} \mathrm{O}$ & $110-140$ & $153.5(122)$ & 19.85 & 19,29 & $350-470 * *$ & 80.75 & 78.84 & $\mathrm{Mn}_{2} \mathrm{O}_{3}$ \\
\hline $\mathrm{Cu}(5 \mathrm{PCA})_{2} \cdot 6 \mathrm{H}_{2} \mathrm{O}$ & $80-167$ & 200.7 (95.6) & 26.13 & 25.86 & $245-384$ & 82.95 & 80.94 & $\mathrm{CuO}$ \\
\hline
\end{tabular}

$5 \mathrm{PCA}-\mathrm{C}_{5} \mathrm{H}_{3} \mathrm{~N}_{2} \mathrm{O}_{2}$ (pyrimidine-5-carboxylate); $\Delta T_{1}$-temperature range of dehydration; $\Delta T_{2}$-temperature range of degradation of anhydrous complex to suitable oxide; *-further transformation of $\mathrm{Co}_{3} \mathrm{O}_{4}$ oxide into $\mathrm{CoO}$ oxide is observed; **-further transformation of $\mathrm{Mn}_{2} \mathrm{O}_{3}$ oxide into $\mathrm{Mn}_{3} \mathrm{O}_{4}$ oxide is observed
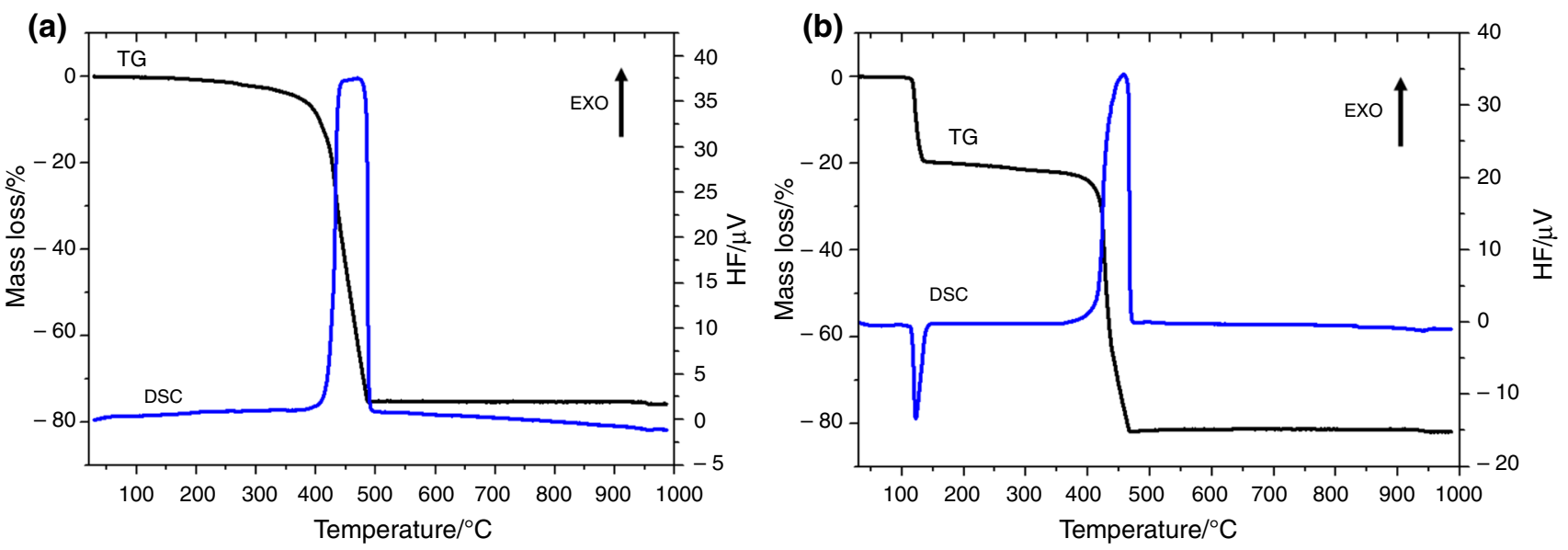

Fig. 13 TG and DSC curves of manganese(II) complexes with: a pyrimidine-2-carboxylic acid; b pyrimidine-5-carboxylic acid
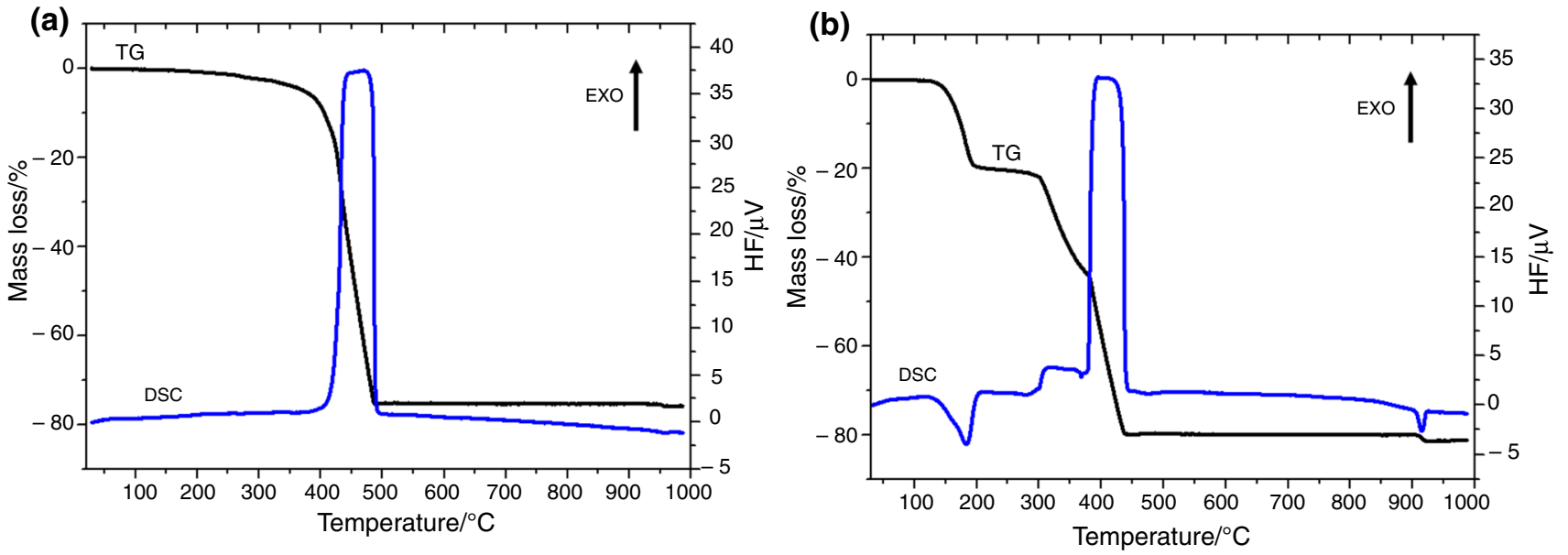

Fig. 14 TG and DSC curves of cobalt(II) complexes with: a pyrimidine-2-carboxylic acid; b pyrimidine-5-carboxylic acid

vibrations of aromatic ring $v(\mathrm{CC})$ and $v(\mathrm{NC})$ and deformation vibrations of $\mathrm{CH}$ moieties [63]. Ammonia molecules were detected among the gaseous products of complex thermal decomposition due to the presence of very diagnostic double peak bands at 967 and $933 \mathrm{~cm}^{-1}$.
At higher temperature, only carbon oxides and traces of water are evolved.

Cobalt(II) pyrimidine-5-carboxylate tetrahydrate is stable in the inert atmosphere to $127{ }^{\circ} \mathrm{C}$. Next, the dehydration process occurs with water molecules evolution in 

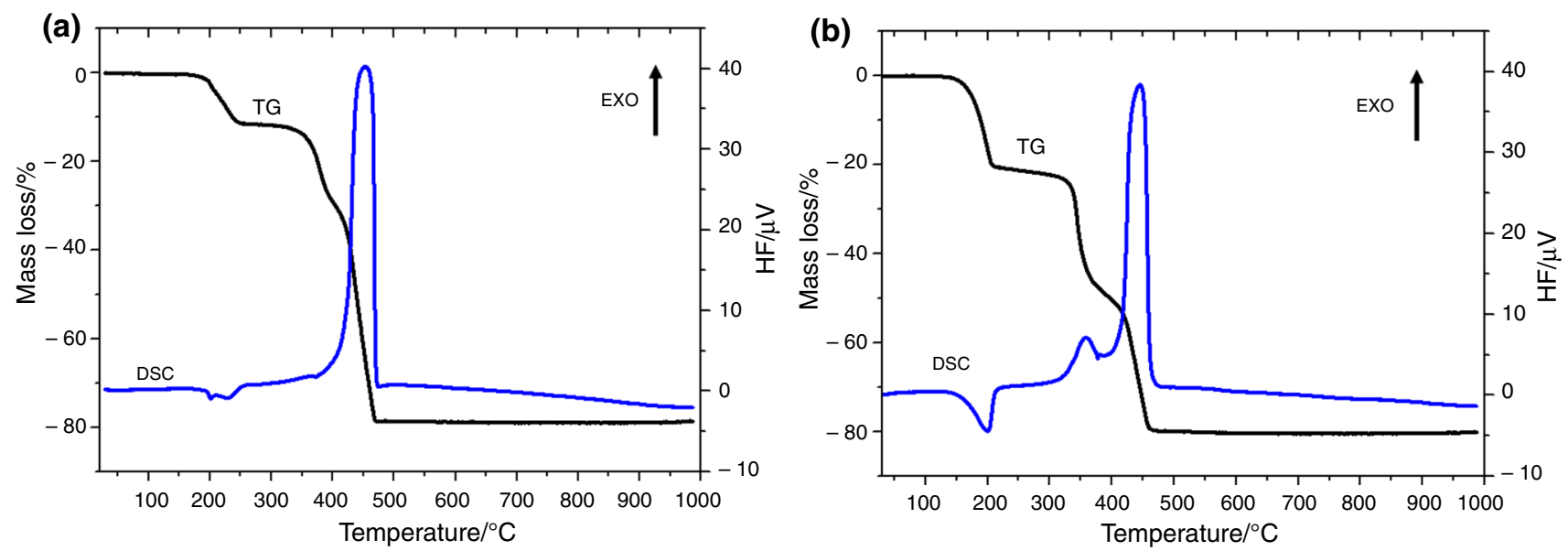

Fig. 15 TG and DSC curves of nickel(II) complexes with: a pyrimidine-2-carboxylic acid; b pyrimidine-5-carboxylic acid
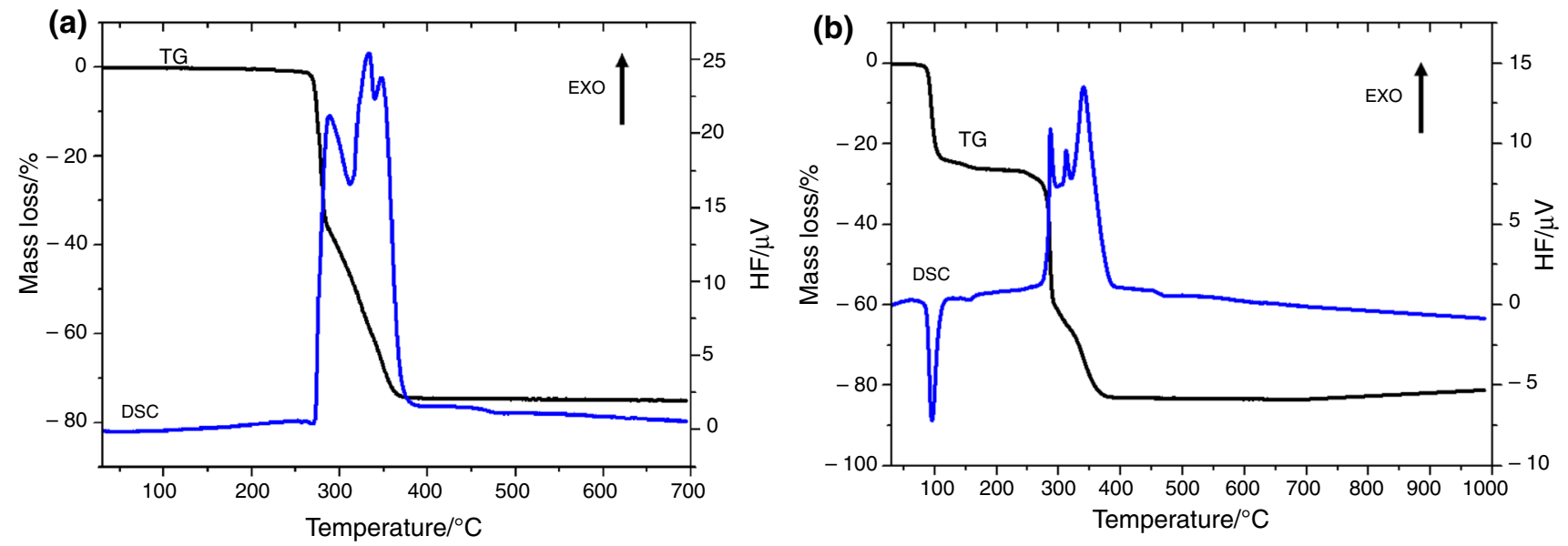

Fig. 16 TG and DSC curves of copper(II) complexes with: a pyrimidine-2-carboxylic acid; b pyrimidine-5-carboxylic acid
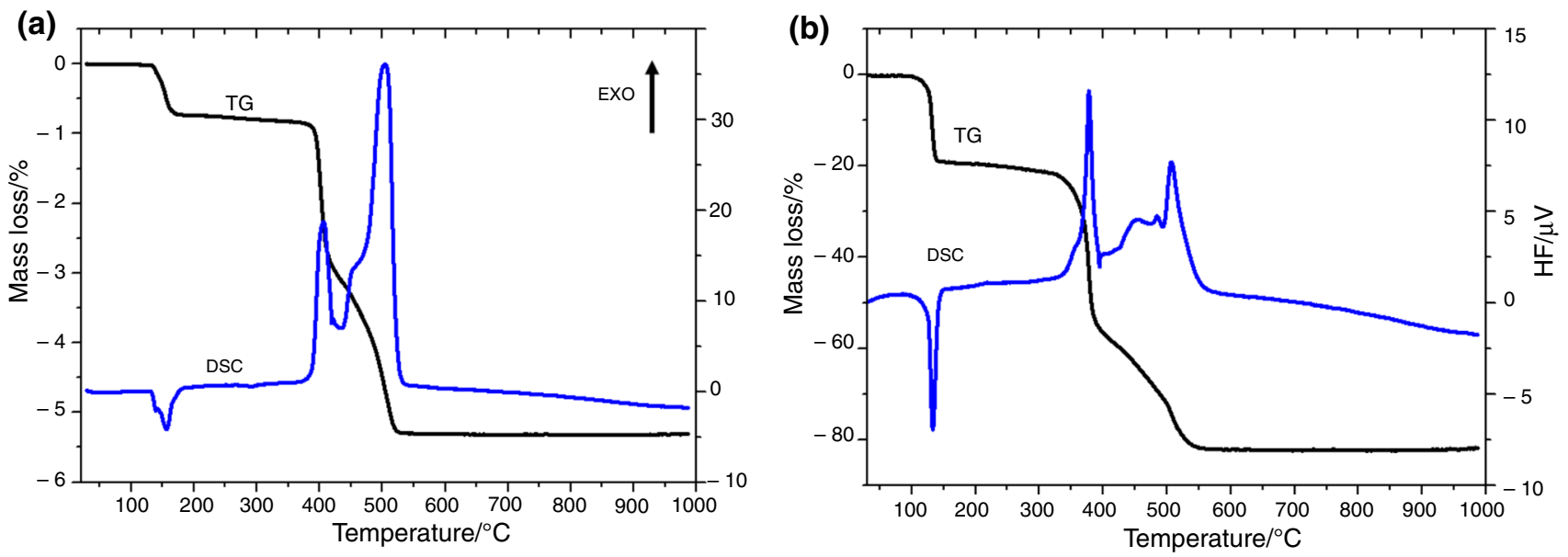

Fig. 17 TG and DSC curves of zinc(II) complexes with: a pyrimidine-2-carboxylic acid; b pyrimidine-5-carboxylic acid

the range $130-210{ }^{\circ} \mathrm{C}$. The FTIR spectra exhibit diagnostic bands derived from the stretching and deformation vibrations of water (Fig. 18). The anhydrous compound is stable to $310{ }^{\circ} \mathrm{C}$. Further heating leads to the degradation of the pyrimidine-5-carboxylate ligand with the evolution of carbon dioxide, ammonia and pyrimidine molecules at 

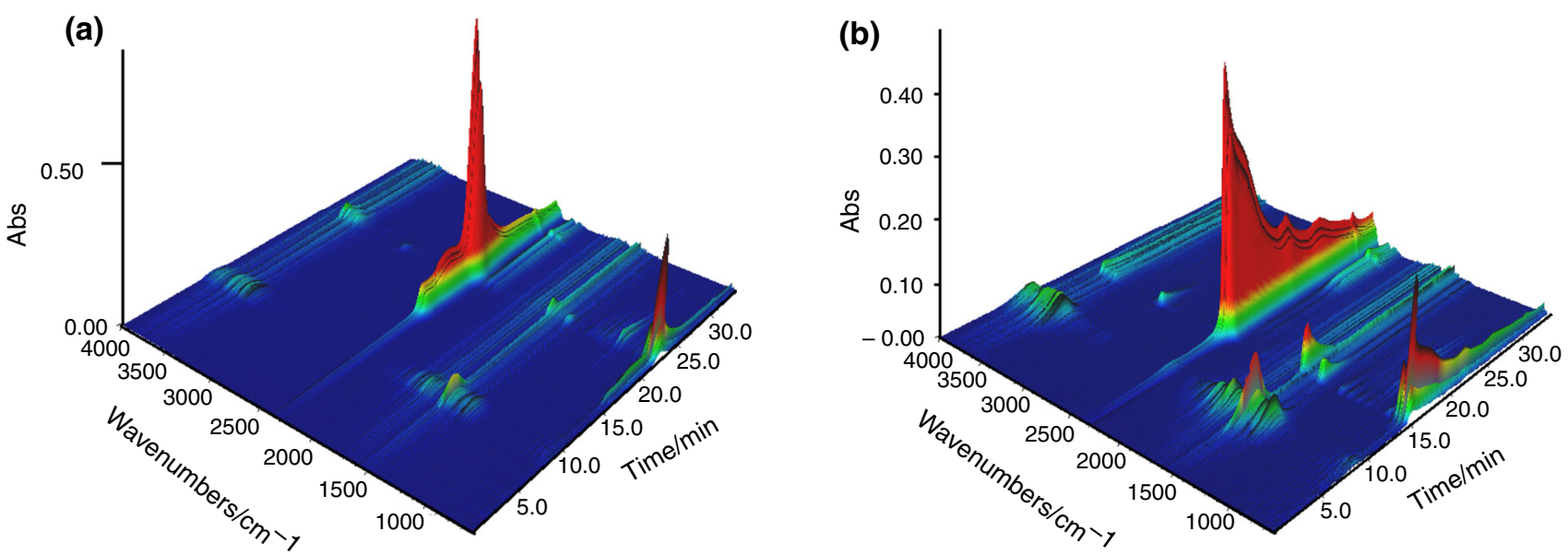

Fig. 18 FTIR spectra of gaseous products evolved during the decomposition of: a $\operatorname{Co}(2 \mathrm{PCA})_{2} \cdot 2.5 \mathrm{H}_{2} \mathrm{O} ; \mathbf{b} \mathrm{Co}(5 \mathrm{PCA})_{2} \cdot 4 \mathrm{H}_{2} \mathrm{O}$

the same time. Compared with the previously described thermal decomposition of cobalt(II) pyrimidine-2-carboxylate, the bands derived from the pyrimidine molecules are more intense. In the wavenumber region $3100-3000 \mathrm{~cm}^{-1}$, there can be distinguished three peaks at 3086,3055 and $3040 \mathrm{~cm}^{-1}$ from the stretching vibrations of $\mathrm{CH}$. In the lower wavenumber region, there are observed several double bands with the maxima at: 1574, $1507 \mathrm{~cm}^{-1}$; 1436, $1387 \mathrm{~cm}^{-1} ; 1230,1209 \mathrm{~cm}^{-1}$ and 1151 , $1140 \mathrm{~cm}^{-1}$ assigned to the stretching and different modes of deformation vibrations of $\mathrm{CC}, \mathrm{CN}$ and $\mathrm{CH}$ moieties [63]. Carbon monoxide is evolved above $600{ }^{\circ} \mathrm{C}$.

\section{Conclusions}

Two series of novel metal(II) complexes with pyrimidine2-carboxylic and pyrimidine-5-carboxylic acid were obtained and characterized. The work allowed to assess the influence of selected metals on the electronic structure and antioxidant properties of the pyrimidinecarboxylic acids. The influence of metals on the above properties was evaluated depending on the location of the carboxyl group relative to the heteroatoms in the aromatic ring. As a result of synthesis, some complexes were obtained in a crystalline form, which allowed for precise determination of the structure using X-ray diffraction. In addition, theoretical calculations of some structures were made, which allowed for a broader interpretation of the obtained results. Two ligands (pyrimidine-2-carboxylic acid and pyrimidine-5carboxylic acid) were selected for the experimental tests.

Taking into account obtained results several conclusions can be drawn:

1. The metal-ligand coordination mode in complexes depends on the position of the carboxylic group in relation to positions of the heteroatoms in the aromatic rings of acids. In the case of metal complexes with pyrimidine-2-carboxylic acid, the metal ions are linked to the ligand via the monodentate carboxylate group and the nitrogen atom of the aromatic ring. In the case of metal complexes with pyrimidine-5-carboxylic acid, the metal ions are only attached to the ligand via the nitrogen atom. These conclusions were confirmed by single-crystal X-ray diffraction method as well as spectroscopic (IR, Raman) investigations.

2. Water molecules in hydrated form of complexes play role of monodentate ligands. Only in copper(II) pyrimidine-5-carboxylate, two additional water molecules are in inner coordination sphere.

3. The analysis of spectroscopic data (IR, Raman) and theoretical calculations (aromaticity indexes) showed that transition $3 \mathrm{~d}$ metals cause changes in the electronic charge distribution of the ligands. This effect is the greatest for the pyrimidine-5-carboxylates in where the metal ions are coordinated directly to the aromatic ring (by nitrogen atom). The metals can stabilize the electron system of pyrimidine-2-carboxylate ligand, while in the case of pyrimidine-5-carboxylate ligand decrease in aromaticity is observed.

4. Theoretical calculations (the SOD activity) have shown that the copper complex of pyrimidine-2-carboxylic acid has lower antioxidant activity than the copper complexes of pyrimidine-5-carboxylic acids.

5. The metal coordination mode also affects the thermal stability of the studied complexes. Thermal analysis has shown that the metal complexes with pyrimidine-2carboxylic acid (with the exception of the manganese complex) exhibit a higher thermal stability compared to the metal pyrimidine-5-carboxylates. The final products of thermal degradation in the air atmosphere of studied complexes are suitable metal oxides. The 
research shows that complexes of transition metals with pyrimidine carboxylic acids are more thermally stable when the metal is coordinated through the carboxyl group and the nitrogen atom of the pyrimidine ring than complexes in which the metal is coordinated only through the nitrogen atom of the pyrimidine ring.

6. Investigated metal complexes decompose in nitrogen atmosphere with releasing of water, carbon oxides, ammonia and pyrimidine molecules.

Acknowledgements The studies have been carried out in the framework of the Project No. S/WBiIS/3/2017 and financed from the funds for science Ministry of Science and Higher Education.

Open Access This article is distributed under the terms of the Creative Commons Attribution 4.0 International License (http://creative commons.org/licenses/by/4.0/), which permits unrestricted use, distribution, and reproduction in any medium, provided you give appropriate credit to the original author(s) and the source, provide a link to the Creative Commons license, and indicate if changes were made.

\section{References}

1. Holm RH, Kennepohl P, Solomon EI. Structural and functional aspects of metal sites in biology. Chem Rev. 1996;96(7):2239-314.

2. Salvemini D, Riley DP, Cuzzocrea S. SOD mimetics are coming of age. Nat Rev Drug Discov. 2002;1(5):367-74.

3. Siddiqi ZA, Khalid M, Kumar S, Shahid M, Noor S. Antimicrobial and SOD activities of novel transition metal complexes of pyridine-2,6-dicarboxylic acid containing 4-picoline as auxiliary ligand. Eur J Med Chem. 2010;45(1):264-9.

4. Siddiqi ZA, Shahid M, Khalid M, Kumar S. Antimicrobial and SOD activities of novel transition metal ternary complexes of iminodiacetic acid containing $\alpha$-diimine as auxiliary ligand. Eur $\mathbf{J}$ Med Chem. 2009;44(6):2517-22.

5. Dabrowiak JC. Metals in medicine. Hoboken: Wiley; 2017.

6. Gielen M, Tiekink ER, editors. Metallotherapeutic drugs and metal-based diagnostic agents: the use of metals in medicine. Hoboken: Wiley; 2005.

7. Kalinowska M, Świderski G, Matejczyk M, Lewandowski W. Spectroscopic, thermogravimetric and biological studies of $\mathrm{Na}(\mathrm{I})$, $\mathrm{Ni}(\mathrm{II})$ and $\mathrm{Zn}$ (II) complexes of quercetin. J Therm Anal Calorim. 2016;126(1):141-8.

8. Kalinowska M, Piekut J, Bruss A, Follet C, Sienkiewicz-Gromiuk J, Świsłocka R, Lewandowski W. Spectroscopic (FT-IR, FTRaman, ${ }^{1} \mathrm{H},{ }^{13} \mathrm{C}$ NMR, UV/Vis), thermogravimetric and antimicrobial studies of $\mathrm{Ca}(\mathrm{II}), \mathrm{Mn}(\mathrm{II}), \mathrm{Cu}(\mathrm{II}), \mathrm{Zn}$ (II) and $\mathrm{Cd}(\mathrm{II})$ complexes of ferulic acid. Spectrochim Acta, Part A. 2014;122:631-8.

9. Samsonowicz M, Kamińska I, Kalinowska M, Lewandowski W. Alkali metal salts of rutin-synthesis, spectroscopic (FT-IR, FTRaman, UV-Vis), antioxidant and antimicrobial studies. Spectrochim Acta, Part A. 2015;151:926-38.

10. Koczoń P, Piekut J, Borawska M, Świsłocka R, Lewandowski W. The relationship between chemical structure and antimicrobial activity of selected nicotinates, p-iodobenzoates, picolinates and isonicotinates. Spectrochim Acta, Part A. 2005;61(8):1917-22.

11. Kalinowska M, Laderiere B, Champagne P, Kowczyk-Sadowy M, Lewandowski W. $\mathrm{Mn}(\mathrm{II}), \mathrm{Cu}(\mathrm{II})$ and $\mathrm{Cd}(\mathrm{II})$ p-coumarates:
FT-IR, FT-Raman, ${ }^{1} \mathrm{H}$ and ${ }^{13} \mathrm{C}$ NMR and thermogravimetric studies. Spectrochim Acta, Part A. 2013;103:264-71.

12. Świderski G, Kalinowska M, Rusinek I, Samsonowicz M, Rzączyńska Z, Lewandowski W. Spectroscopic (IR, Raman) and thermogravimetric studies of 3d-metal cinchomeronates and dinicotinates. J Therm Anal Calorim. 2016;126(3):1521-32.

13. Kalinowska M, Borawska M, Świsłocka R, Piekut J, Lewandowski W. Spectroscopic (IR, Raman, UV, ${ }^{1} \mathrm{H}$ and ${ }^{13} \mathrm{C}$ NMR) and microbiological studies of $\mathrm{Fe}(\mathrm{III}), \mathrm{Ni}(\mathrm{II}), \mathrm{Cu}(\mathrm{II}), \mathrm{Zn}$ (II) and Ag(I) picolinates. J Mol Struct. 2007;834:419-25.

14. Kalinowska M, Świsłocka R, Lewandowski W. Zn(II), Cd(II) and $\mathrm{Hg}(\mathrm{I})$ complexes of cinnamic acid: FT-IR, FT-Raman, ${ }^{1} \mathrm{H}$ and ${ }^{13} \mathrm{C}$ NMR studies. J Mol Struct. 2011;993(1-3):404-9.

15. Świderski G, Lewandowska H, Świsłocka R, Wojtulewski S, Siergiejczyk L, Wilczewska A. Thermal, spectroscopic (IR, Raman, NMR) and theoretical (DFT) studies of alkali metal complexes with pyrazinecarboxylate and 2,3-pyrazinedicarboxylate ligands. J Therm Anal Calorim. 2016;126(1):205-24.

16. Świderski G, Kalinowska M, Malejko J, Lewandowski W. Spectroscopic (IR, Raman, UV and fluorescence) study on lanthanide complexes of picolinic acid. Vib Spectrosc. 2016;87:81-7.

17. Xu DJ, Zhang BY, Yang Q, Nie JJ. Diaqua-bis(pyrimidine-2carboxylic acid- $\kappa 2 \mathrm{~N}, \mathrm{O})$ cobalt(II) dichloride. Acta Crystallogr Sect E. 2008;64:m77.

18. Zhang BY, Yang Q, Nie JJ. Bis(pyrimidine-2-carboxyl-ato- $\kappa 2 \mathrm{~N}$, O)copper(II). Acta Crystallogr Sect E. 2008;64:m7.

19. Aekeroy CB, Desper J, Levin B, Valdez-Martines J. Robust building blocks for inorganic crystal engineering. Inorg Chim Acta. 2006;359:1255-62.

20. Orjiekwe CL, Fabiyi FA, Edward DA. Synthesis and characterization of new picolinate metal complexes. Synth React Inorg, Met-Org, Nano-Met Chem. 2005;35(9):695-702.

21. Okabe N, Koizumi M. Diaquabis (2-pyridinecarboxylato-N, O) manganese(II). Acta Crystallogr Sect C. 1998;54(3):288-90.

22. Nie FM, Fang T, Wang SY, Ge HY. Synthesis and structures of pyridinecarboxylate-containing zinc(II) complexes in dien and tren system. Inorg Chim Acta. 2011;365(1):325-32.

23. Waizumi K, Takuno M, Fukushima N, Masuda H. Structures of pyridine carboxylate complexes of cobalt(II) and copper(II). J Coord Chem. 1998;44:269-79.

24. Batten SR, Harris AR. trans-Tetraaquabis(pyridine-3-carboxylate-kN)nickel(II). Acta Crystallogr Sect E. 2001;57:9-11.

25. Prasanna S, Bijini BR, Babu KR, Eapen SM, Deepa M, Nair CMK. Growth and characterisation of a novel polymer of manganese(II) nicotinate single crystal. J Cryst Growth. 2011;333(1):36-9.

26. Hauptmann R, Kondo M, Kitagawa S. Crystal structure of bis(4aminobenzoato)aquacadmium dihydrate, $\left[\mathrm{Cd}\left(\mathrm{H}_{2} \mathrm{NC}_{6} \mathrm{H}_{4} \mathrm{COO}\right)_{2}(-\right.$ $\left.\left.\mathrm{H}_{2} \mathrm{O}\right)\right]_{\mathrm{n}} \cdot 2 n \mathrm{H}_{2} \mathrm{O}$. Z Kristallogr NCS. 2000;215:169-72.

27. Chapman ME, Ayyappan P, Foxman BM, Yee GT, Lin W. Synthesis, X-ray structures, and magnetic properties of copper(II) pyridinecarboxylate coordination networks. Cryst Growth Des. 2001;1(2):159-63.

28. Lu TB, Luck RL. Interpenetrating nets in cis-bis (pyridine-4carboxylate) nickel(II). Acta Crystallogr Sect C. 2002;58(3):152-4.

29. Vargová Z, Zeleòák V, Císaøová I, Györyová K. Correlation of thermal and spectral properties of zinc(II) complexes of pyridinecarboxylic acids with their crystal structures. Thermochim Acta. 2004;423(1):149-57.

30. Allan JR, Geddes WC, Hindle CS, Orr AE. Thermal analysis studies on pyridine carboxylic acid complexes of zinc(II). Thermochim Acta. 1989;153:249-56. 
31. Artetxe B, San Felices L, Reinoso S, Martin-Caballero J, Gutierrez-Zorrilla JM. Diaqua-trans-bis(pyridazine-3-carboxylato-К2N2, O)cobalt(II). Acta Crystallogr Sect E. 2013;69:420-1.

32. Starosta W, Leciejewicz J. trans-Tetraaquabis(pyridazine-4-carboxylato-KO) magnesium(II) dihydrate. Acta Crystallogr Sect E. 2011;67:m316.

33. Longley DB, Harkin DP, Johnston PG. 5-Fluorouracil: mechanisms of action and clinical strategies. Nat Rev Cancer. 2003;3(5):330-8.

34. Yerragunta V, Patil P, Anusha V, Kumaraswamy T, Suman D, Samhitha T. Pyrimidine and its biological activity: a review. Pharma Tutor. 2013;1(2):39-44.

35. Kleschick WA, Costales MJ, Dunbar JE, Meikle RW, Monte WT, Pearson NR, Sinder SW, Vinogradoff AP. New herbicidal derivatives of 1,2,4-triazolo [1,5-a] pyrimidine. Pesticide Sci. 1990;29(3):341-55.

36. Smith LH, Baker FA. Pyrimidine metabolism in man. I. The biosynthesis of orotic acid. J Clin Invest. 1959;38(5):798-809.

37. Hallanger LE, Laakso JW, Schultze MO. Orotic acid in milk. J Biol Chem. 1953;202:83-9.

38. Löffler M, Carrey EA, Zameitat E. Orotate (orotic acid): an essential and versatile molecule. Nucleos Nucleot Nucl Acid. 2016;35(10-12):566-77.

39. Frisch M, Trucks GW, Schlegel HB, Scuseria GE, Robb MA, Cheeseman JR, Scalmani G, Barone V, Mennucci B, Petersson GA. Gaussian 09, revision A. 02. Wallingford: Gaussian, Inc.; 2009.

40. Breda S, Reva ID, Lapinski L, Nowak MJ, Fausto R. Infrared spectra of pyrazine, pyrimidine and pyridazine in solid argon. J Mol Struct. 2006;786(2-3):193-206.

41. Destexhe A, Smets J, Adamowicz L, Maes G. Matrix isolation FT-IR studies and ab initio calculations of hydrogen-bonded complexes of molecules modeling cytosine or isocytosine tautomers. 1. Pyridine and pyrimidine complexes with $\mathrm{H}_{2} \mathrm{O}$ in $\mathrm{Ar}$ matrixes. J Phys Chem. 1994;98(5):1506-14.

42. Krygowski TM, Cyrański M. Separation of the energetic and geometric contributions to the aromaticity of $\pi$-electron carbocyclics. Tetrahedron. 1996;52(5):1713-22.

43. Krygowski TM, Cyrański M. Separation of the energetic and geometric contributions to the aromaticity. Part IV. A general model for thep-electron systems. Tetrahedron. 1996;52:10255-64.

44. Bird C. A new aromaticity index and its application to fivemembered ring heterocycles. Tetrahedron. 1985;41:1409-14.

45. Diffraction RO, Rigaku Oxford Diffraction. CrysAlisPro software system, version 1.171.38.46. Oxford: Rigaku Corporation; 2017.

46. Dolomanov OV, Bourhis LJ, Gildea RJ, Howard JAK, Poschmann H. OLEX2: a complete structure solution, refinement and analysis program. J Appl Cryst. 2009;42(2):339-41.

47. Sheldrick GM. A short history of SHELX. Acta Crystallogr Sect A. 2008;64:112-22.

48. Oliveira G, Martin JML, Proft F, Geerlings P. Electron affinities of the first- and second-row atoms: benchmark ab initio and density-functional calculations. Phys Rev A. 1999;60:1034-45.
49. Ji HF, Zhang HY. A new strategy to combat Alzheimer's disease. Combining radical-scavenging potential with metal-protein-attenuating ability in one molecule. Bioorg Med Chem Lett. 2005; 15(1):21-4.

50. Minot C. Graphite as an aromatic system. J Phys Chem. 1987;91:6380-5.

51. Zhou Z, Parr RG, Garst JF. Absolute hardness as a measure of aromaticity. Tetrahedron Lett. 1988;29:4843-6.

52. Koczoń P, Dobrowolski JC, Lewandowski W, Mazurek AP. Experimental and theoretical IR and Raman spectra of picolinic, nicotinic and isonicotinic acids. J Mol Struct. 2003;655(1):89-95.

53. Nakamoto K, McCarthy PJ. Spectroscopy and structure of metal chelate compounds. New York: Wiley; 1968.

54. Lewandowski W, Kalinowska M, Lewandowska H. The influence of metals on the electronic system of biologically important ligands. Spectroscopic study of benzoates, salicylates, nicotinates and isoorotates. J Inorg Biochem. 2005;99(7):1407-23.

55. Lewandowski W, Świderski G, Świslocka R, Wojtulewski S, Koczoń P. Spectroscopic (Raman, FT-IR and NMR) and theoretical study of alkali metal picolinates. J Phys Org Chem. 2005;18(9):918-28.

56. Mrozek R, Rzączyńska Z, Sikorska-Iwan M, Jaroniec M, Głowiak T. A new complex of manganese(II) with L- $\alpha$-alanine: structure, spectroscopy and thermal study. Polyhedron. 1999;18:2321-6.

57. Sikorska-Iwan M, Mrozek-Łyszczek R. Application of coupled TG-FTIR system in studies of thermal stability of manganese(II) complexes with amino acids. J Therm Anal Calorim. 2004;78:487-500.

58. Mrozek- $Ł y s z c z e k ~ R$. Thermal investigations of cefadroxil complexeswith transition metals coupled TG-DSC and TG-FTIR techniques. J Therm Anal Calorim. 2004;78:473-86.

59. Łyszczek R, Głuchowska H, Sienkiewicz-Gromiuk J, Mazur L, Tarasiuk B. Coordination polymers of $\mathrm{Na}(\mathrm{I}), \mathrm{Mg}$ (II) and $\mathrm{Co}(\mathrm{II})$ ions based on biphenyl-4,4'-diacetic acid: synthesis, crystal structures and thermal properties. Polyhedron. 2015;99:132-40.

60. Bartyzel A. Effect of molar ratios of reagents and solvent on the complexation process of nickel(II) ions by the $\mathrm{N}_{2} \mathrm{O}_{3}$-donor Schiff base. Polyhedron. 2017;134:30-40.

61. Bartyzel A. Synthesis, thermal study and some properties of $\mathrm{N}_{2} \mathrm{O}_{4}$-donor Schiff base and its $\mathrm{Mn}(\mathrm{III}), \mathrm{Co}(\mathrm{II}), \mathrm{Ni}(\mathrm{II}), \mathrm{Cu}(\mathrm{II})$ and Zn(II) complexes. J Therm Anal Calorim. 2017;127:2133-47.

62. Łyszczek R, Bartyzel A, Głuchowska H, Mazur L, Sztanke M, Sztanke K. Thermal investigations of biologically important fused azaisocytosine-containing congeners and the crystal structure of one representative. J Anal Appl Pyrol. 2018;135:141-51.

63. Breda S, Reva ID, Lapinski L, Nowak MJ, Fausto R. Infrared spectra of pyrazine, pyrimidine and pyridazine in solid argon. J Mol Struct. 2006;786:193-206.

Publisher's Note Springer Nature remains neutral with regard to jurisdictional claims in published maps and institutional affiliations. 